\title{
Las temperaturas del territorio que se extiende desde el Cantábrico Oriental al Valle del Ebro durante el periodo internacional 1961-90.
}

Javier M. Pejenaute Goñi (Profesor-Tutor de Geografía)

\section{RESUMEN SUMMARY}

El presente articulo tiene por objeto el estudio de las temperaturas en el territorio comprendido entre el Cantábrico oriental y el Valle del Ebro, durante el periodo internacional

1961-90. Este territorio está ocupado por las comunidades del

País Vasco, Navarra, La Rioja y

Aragón. Se estudian las temperaturas medias, las máximas, las mínimas, el coeficiente de variación y las heladas. También se incluye en el

análisis anual, el estudio de la amplitud térmica, los quintiles y la tendencia futura.

PALABRAS CLAVE

Climatología. Temperaturas. País Vasco, Navarra, La Rioja, Aragón.

Periodo internacional 1961-90.
The present article aims at studying the temperatures in an area that goes from the cantabrico oriental and Valle del Ebro, for the international period of time going from 1961-90. Four autonomous cornmunities, País Vasco, Navarra, La Rioja and Aragón, are included in this territory. The object of study will be the average, maximum and minimum temperatures, as well as the coefficient of variation and freezes. It will also be included in the annual analysis. the study of thermal amplitude, quintiles, and future trend.

KEYWORDS

Climatology. Temperatures. Pais Vasco, Navarra, La Rioja, Aragón. 1961-90 international period. 


\section{INTRODUCCIÓN}

La temperatura constituye uno de los elementos más importantes en el estudio del clima de una región. En este trabajo se trata de analizar las características térmicas de la transición climática que tiene lugar en el territorio comprendido entre el Cantábrico oriental y el valle del Ebro, durante el periodo internacional 1961-90. Este territorio está ocupado por las comunidades del país Vasco, Navarra, La Rioja y parte de Aragón, y en él se encuentran las ciudades de Bilbao, San Sebastián, Vitoria, Pamplona, Logroño y Zaragoza.

Bien es verdad que siempre ha llamado la atención de los geógrafos ,españoles la diversidad climática del citado territorio que origina a su vez una variedad ecológica y paisajista y, en definitiva, modos distintos de ocupación del territorio. posiblemente sea este espacio de transición, entre el medio oceánico y mediterráneo, el de mayor riqueza comarcal climática de la península de acuerdo con su reducida extensión.

En el estudio se denomina Transición a todo el territorio considerado. Este espacio se divide en varios sectores: Valles Cantábricos (vizcainos, guipuzcoanos y del norte de Navarra), Valles Pirenaicos (Esteribar, Aezkoa, Salazar, Roncal), Cuencas Intermedias (Llanada de Vitoria, corredor del Arakil y Cuencas de Pamplona y Lumbier-Aóiz) y Valle del Ebro (alto Valle del Ebro, o zona de Logroño, Ribera navarra y Navarra Media, y el bajo Valle del Ebro, o zona de Zaragoza).

El periodo 1961-90 objeto de estudio coincide con uno de los años fijados por la Organización Meteorológica Mundial como estándar para poder estudiar el clima de un lugar. Sus datos y sus conclusiones podrán ser comparadas con otros observatorios internacionales de otros lugares del mundo que estudian los mismos años. Este estudio forma parte de un proyecto más amplio que ha sido subvencionado por la caja de Ahorros de Navarra en colaboración con el Centro Asociado de la UNED de Pamplona.

Para la realización de este estudio se han elegido los observatorios más idóneos, teniendo en cuenta la fiabilidad, la disponibilidad de series de larga duración y la situación estratégica a lo largo de todo el territorio objeto de estudio. Se han consultado las Guias resumidas del clima en España correspondientes a los periodos internacionales 1931- $60 \mathrm{Y}$ 1961-90 (Instituto Nacional de Meteorología 1982 y 1997) y los datos completos (año a año y mes a mes) aportados por los Centros Meteorológicos de Aragón-La Rioja y Navarra, y país Vasco. 


\section{LOS CONTRASTES TÉRMICOS ANUALES}

Se ha optado por un análisis primeramente anual, para posteriormente pasar al estacional, más pormenorizado. Para analizar el comportamiento anual se estudian las temperaturas medias y sus gradientes altitudinales, las medias de las máximas o el grado de calor diurno, las medias de las minimas o el grado de frío nocturno, las temperaturas máximas y mínimas absolutas, el coeficiente de variación, la amplitud térmi$\mathrm{ca}$, los quintiles y la recta de tendencia.

La temperatura media anual muestra los contrastes existentes en el territorio de la Transición. Como las distintas comarcas son diferentes según la altitud se ha calculado el gradiente térmico vertical de las temperaturas medias anuales (gráfico $\mathrm{n}^{\circ} 1$ ), siendo de $0,64^{\circ}$ de disminución cada cien metros de altitud a partir de $15,23^{\circ}$ de temperatura 1 .

El Valle del Ebro y los Valles Cantábricos más caldeados, situados cerca del mar y a baja altitud, son los que presentan valores térmicos anuales más elevados con temperaturas medias anuales que alcanzan o superan los trece grados. Pero ambos sectores son totalmente diferentes, aunque el resultado anual sea parecido, como se verá posteriormente en el estudio estacional.

El bajo Valle del Ebro y los sectores más cálidos de los Valles Cantábricos alcanzan los catorce grados (Zaragoza-Aeropuerto $14,6^{\circ}$; BilbaoSondica $14^{\circ}$; Hondarribia $14^{\circ}$ ) y superan en algunas ocasiones en más de un grado a los observatorios más moderados de esta zona (LogroñoAgoncillo $13,4^{\circ}$; Carcastillo-La Oliva $13^{\circ}$; San Sebastián-Igueldo $13^{\circ}$ ). Estos resultados son ligeramente superiores a los registrados en el periodo internacional 1931-60 en los Valles Cantábricos e inferiores en el alto Valle del Ebro (Bilbao-Sondica 14\% ; San Sebastián-Igueldo 13,1 $1^{\circ}$; ZaragozaAeropuerto 14,8 ; Logroño-Agoncillo $13,4^{\circ}$ ).

El área Baztan-Bidasoa, y los valles guipuzcoanos y vizcaínos, se caracterizan por la moderación de las temperaturas anuales, pese a la humedad existente en este periodo (Arditurri 12,6 $6^{\circ}$; Durango 12,4 ; Aranzazu $10,8^{\circ}$ ). Por el contrario, los observatorios situados a cierta alti-

El cálculo se ha realizado a partir de los datos proporcionados por 26 observatorios del territorio considerado anualmente y en las cuatro estaciones del año. El coeficiente de correlación entre la altitud (variable independiente) y la temperatura media anual (variable dependiente) es alto $(0,8511)$. La correlación es clara y la recta de ajuste presenta la ecuación $y=-0,0064 x+15,23$ 
tud en los Valles Cantábricos y los valles meridionales húmedos navarros (Basaburua, Anue, Ultzama), son más fríos y obtienen valores más bajos.

Temperaturas medias anuales más bajas registran las Cuencas Intermedias. La Cuenca de Pamplona es más cálida que la Llanada de Vitoria y que el Corredor del Arakil (Vitoria- Foronda 11,3; Villanueva de Valdegovia $11,4^{\circ}$; Ullivarri- Gamboa $10,8^{\circ}$; Alsasua $11^{\circ}$; Pamplona-Observatorio $12,4^{\circ}$ ). Estos resultados son inferiores a los anotados en el período internacional 1931-60 en la Llanada e iguales en Pamplona (Vitoria-Foronda $11,7^{\circ}$; Pamplona-Observatorio $12,4^{\circ}$ ).

Las temperaturas medias anuales más rigurosas se dan en los Valles Pirenaicos (Abaurrea Alta $8,4^{\circ}$ ). Se trata de los lugares más fríos de la Transición, debido a la continentalidad y sobre todo a la altitud. El enclave de Valcarlos, abierto a las influencias oceánicas, es una excepción, ya que presenta características térmicas similares a los Valles Cantábricos. La Llanada Espinal- Burguete-Roncesvalles, la cabecera del Valle Esteribar y los Valles de Salazar y Roncal resultan bastante fríos.

Existen diferencias importantes si se observan las temperaturas medias anuales de la serie. El año más frío fue 1972 en Zaragoza-Aeropuerto y San Sebastián-Igueldo, 1964 en Pamplona y 1969 en Abaurrea Alta $\left(13,3^{\circ} ; 12,3^{\circ} ; 11,3^{\circ} ; Y 7,3^{\circ}\right.$ respectivamente) y el más cálido 1989 en San Sebastián, Zaragoza y Abaurrea Alta y 1961 en Pamplona $\left(14,6^{\circ} ; 16^{\circ}\right.$; $10,6^{\circ}$ y $13,9^{\circ}$ respectivamente), por lo que el recorrido alcanza los dos grados en todos los observatorios y los dos y medio en Pamplona y Zaragoza (San Sebastián-Igueldo 2,3 $3^{\circ}$ Pamplona-Observatorio 2,6 $6^{\circ}$; Zaragoza-Aeropuerto 2,7; Abaurrea Alta $2^{\circ}$ ).

El coeficiente de variación ${ }^{2}$, que nos permite comparar la dispersión de las temperaturas medias anuales, es bajo y sólo en Alsasua y Abaurrea Alta presenta valores amplios próximos a diez (Abaurrea Alta $10 \%$ ). El resto se sitúa alrededor de cinco (Logroño-Agoncillo 4\%; San Sebastián-Igueldo 4\%; Santesteban 5\%; Vitoria-Foronda 4\%; Pamplona-Observatorio 5\%)

La temperatura media de las máximas anual da una idea del grado de calor que se alcanza al mediodía o primeras horas de la tarde. El Valle del Ebro resulta el lugar más cálido en las horas centrales del día (ZaragozaAeropuerto $20,1^{\circ}$ ) y supera en uno o dos grados a los valores térmicos de

2 El Coeficiente de variación que compara la desviación estándar y en este caso la temperatura media anual, sirve para ver la dispersión existente dentro de las temperaturas. 
Navarra Media, la Ribera y los Valles Cantábricos más soleados y a menor altitud (Logroño-Agoncillo 18,6 $6^{\circ}$; Carcastillo-La Oliva 19,2 $2^{\circ}$; Olite $19,1^{\circ}$; Bilbao-Sondica $18,8^{\circ}$; Hondarribia $18,3^{\circ}$ ). Resultados bastante parecidos a los del periodo internacional anterior, 1931-60, (Zaragoza- Aeropuerto $20^{\circ}$; Logroño-Agoncillo $18,5^{\circ}$; Bilbao-Sondica $18,6^{\circ}$ ).

Las Cuencas Intermedias y los observatorios más fríos de los Valles Cantábricos obtienen temperaturas inferiores. La Cuenca de Pamplona tiene mayor grado de calor al mediodía que San Sebastián y Vitoria (Pamplona-Observatorio 17,2 $2^{\circ}$ San Sebastián-Igueldo $16^{\circ}$; Ardituri $17,1^{\circ}$; Durango $16,8^{\circ}$; Vitoria-Foronda $16,2^{\circ}$; Ullivarri-Gamboa $15,6^{\circ}$ ). Los Valles Pirenaicos registran los valores más bajos del territorio, pues resultan poco calurosos, incluso al mediodía, debido a la altitud en que se encuentran (Abaurrea Alta 12,3 $3^{\circ}$. Resultados parecidos en San Sebastián a los anotados en el periodo internacional 1931-60 y medio grado inferior en los otros (Pamplona-Observatorio 17,6 $6^{\circ}$; San Sebastián-Igueldo 15,9 ; Vitoria-Foronda $\left.16,4^{\circ}\right)$.

Los observatorios de la Transición en algunas ocasiones pueden alcanzar temperaturas máximas absolutas del año elevadas, conseguidas en los días de verano con olas de calor del sur. En los valles Cantábricos, Cuenca de Pamplona y Cuenca del Ebro se han alcanzado los cuarenta grados, por lo menos en alguna ocasión, mientras que en los Valles Pirenaicos solamente se ha llegado a los treinta y cinco grados (Bilbao-Sondica 41,7 ; San Sebastián-Igueldo $38^{\circ}$; Vitoria-Foronda $38,6^{\circ}$

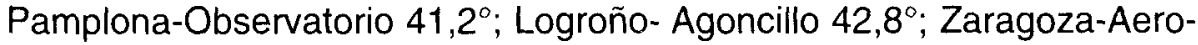
puerto $42,6^{\circ}$; Abaurrea Alta $35^{\circ}$ ).

Existen diferencias importantes entre unos años y otros en cuanto a las temperaturas medias de las máximas. El año más frío en San Sebastián fue 1963, en Pamplona 1969 y en Zaragoza fue 1972 (San Sebastián-Igueldo $15,3^{\circ}$; Pamplona- Observatorio $16^{\circ}$; Zaragoza-Aeropuerto $18,6^{\circ}$ ) y el más cálido 1989 en San Sebastián, 1961 en Pamplona y 1990 en Zaragoza (San Sebastián-Igueldo $17,6^{\circ}$; Pamplona-Observatorio $19,8^{\circ}$; Zaragoza-Aeropuerto $21,5^{\circ}$ ), por lo que el recorrido es de más de tres grados en Pamplona, casi tres en Zaragoza y más de dos grados en San Sebastián.

La temperatura media de las mínimas anual muestra el grado de frío nocturno que se alcanza en las horas más frias de la noche. Los Valles Cantábricos y el bajo Valle del Ebro son los sectores más moderados, que registran una temperatura media de las mínimas anuales entre los 
nueve y diez grados (San Sebastián-Igueldo $10^{\circ}$; Hondarribia $9,7^{\circ}$; Zaragoza-Aeropuerto $9,1^{\circ}$ ). El alto Valle del Ebro, los Valles Cantábricos más moderados, la Rioja y la Ribera Estellesa, tienen registros algo inferiores (Logroño- Agoncillo 8, $3^{\circ}$; Arditurri 8,2 $2^{\circ}$; Durango 8, $1^{\circ}$; Aranzazu 7,7 $7^{\circ}$. Resultados inferiores en Zaragoza y San Sebastián y parecidos en Logroño a los del periodo internacional, 1931- 60 (San Sebastián-Igueldo 10,3; Logroño-Agoncillo $8,2^{\circ}$; Zaragoza-Aeropuerto 9,7 )

Las Cuencas Intermedias tienen noches más frias, debido principalmente a la altitud y a ser cuencas cerradas rodeadas de montañas en donde la irradiación nocturna es notoria, así como el riesgo de embalsamiento de masas de aire frías (Vitoria-Foronda $6,1^{\circ}$; Ullivarri-Gamboa $6,1^{\circ}$; Pamplona-Observatorio $7,5^{\circ}$ ). El Corredor del Arakil, especie de pasillo estrecho entre las Sierras de Aralar y Andia, resulta el más frío. Resultados inferiores en Vitoria y superiores en Pamplona a los del periodo internacional 1931- 60 (Pamplona-Observatorio 7,1 $1^{\circ}$; Vitoria-Foronda $7^{\circ}$ )

Los Valles Pirenaicos, son los lugares con temperaturas mínimas más bajas que no alcanzan los cuatro grados. Estamos ante noches con valores térmicos muy bajos debido a que el calor del mediodía se pierde con facilidad en cuanto el sol desaparece y entra la noche. Por otra parte, la compartimentación del relieve y la orografía complicada y elevada, supone una acumulación de frío invernal en meses más moderados de otoño y primavera.

Las temperaturas mínimas absolutas muestran el ambiente frío que pueden alcanzar los distintos sectores con olas de frío que han tenido lugar sobre todo en enero y febrero. En todos los lugares se han alcanzado los diez grados bajo cero. En las Cuencas Intermedias, Valle del Ebro y Valles Pirenaicos se han llegado a los quince grados bajo cero (BilbaoSondica $-8,6^{\circ}$; San Sebastián-Igueldo $-12^{\circ}$; Logroño- Agoncillo $-11,6^{\circ}$; Zaragoza-Aeropuerto $-11,4^{\circ}$; Vitoria- Foronda $-17,8^{\circ}$; Pamplona-Observatorio $-16,2^{\circ}$; Abaurrea Alta $-18^{\circ}$ ). Estos registros tan bajos se obtuvieron principalmente en la ola de frío de enero de 1985 que dejó el territorio sumido en un mar de frío.

Existen diferencias importantes entre unos años y otros en cuanto a las temperaturas medias de las mínimas. El año con más frío nocturno en San Sebastián y en Zaragoza fue 1972 y en Pamplona 1963 (San Sebastián-Igueldo 9,2 ; Pamplona-Observatorio 5,9 $9^{\circ}$; Zaragoza-Aeropuerto $8,1^{\circ}$ ) y el más cálido 1989 en los tres observatorios (San SebastiánIgueldo 11, $6^{\circ}$; Pamplona-Observatorio 8,6 $6^{\circ}$; Zaragoza- Aeropuerto $10,6^{\circ}$ ), por lo que el recorrido es cercano a dos grados y medio (San SebastiánIgueldo 2,4 $4^{\circ}$; Pamplona- Observatorio 2,5 $5^{\circ}$; Zaragoza-Aeropuerto $2,5^{\circ}$ ). 
Se han calculado los quintiles de las temperaturas medias anuales en los observatorios más representativos con el objeto de ver los tipos de tiempo que predominaron en cada una de las tres décadas del periodo internacional 1961-90. Del análisis de sus datos se deduce que la década de los ochenta, la más reciente, es mucho más cálida que las dos anteriores en todas las comarcas; la del sesenta se puede catalogar de moderada; y la del setenta de fría, pues no anota apenas tiempos cálidos y muy cálidos. Vamos a fijarnos en la década de los ochenta que fue la más cálida. De los diez años sólo uno resulta muy frío, salvo en Abáurrea Alta que son dos; Pamplona tiene en esta última década ocho años cálidos y muy cálidos y siete el resto de los observatorios (Cuadro 1).

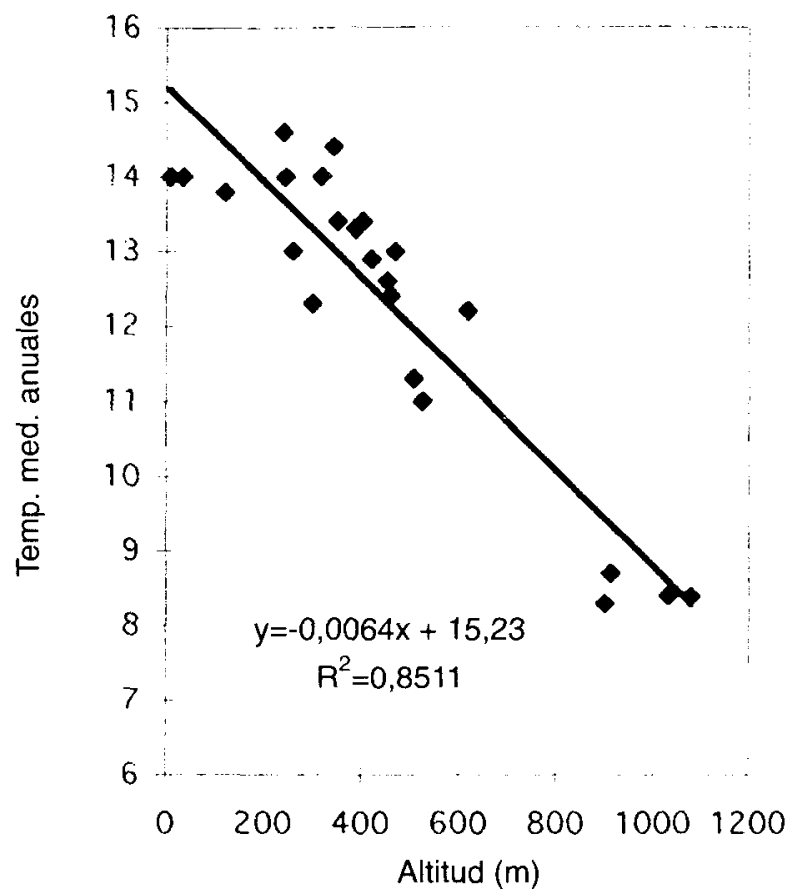

Cuadro 1. Gradiente térmico vertical de las temperaturas medias anuales

El estudio del número de días de helada al año da una idea más completa del frío en las comarcas del territorio estudiado. Los Valles Pirenaicos y las altas montañas del territorio registran alrededor de cien días de helada al año, es decir casi la tercera partes de los días del año registran 
helada (Abaurrea Alta 110,5 días de helada; Jaurrieta 113,9; Remendia 97,2; Urbasa 111). Algunos lugares del Valle del Ebro y las Cuencas Intermedias son muy fríos y registran cifras cercanas, e incluso superiores, a los cuarenta días de helada (Olite 44 días de helada; Carcastillo-la Oliva 60; Yesa 48; Vitoria-Foronda 47; Pamplona-Observatorio 45). El Corredor del Arakil, encajonado entre las sierras de Aralar y urbasa-Andia, es un lugar más frio que la Llanada y la Cuenca de Pamplona (Alsasua 53 días de helada). El bajo Valle del Ebro anota menos días de helada que en los sectores anteriores (Logroño-Agoncillo 24; Zaragoza-Aeropuerto 27). Resultados algo distintos, menos en Logroño, al período internacional anterior (Logroño-Agoncillo 25 días de helada al año; Vitoria-Foronda 40; Zaragoza-Aeropuerto 20).

Cuadro I. Años muy fríos, fríos, templados, cálidos y muy cálidos en las tres décadas del periodo 1961-90 (quintiles sobre las temperaturas medias anuales)

\begin{tabular}{ccccccccccccccccccccccc}
\hline Décadas & \multicolumn{1}{c}{ San Sebastián-lgu } & \multicolumn{1}{c}{ Pamplona-Obs } & \multicolumn{1}{c}{ Logroño-Aragoncillo } & \multicolumn{1}{c}{ Abaurrea Alta } \\
\hline & Mf & F & T & C & MC & Mf & F & T & C & MC & Mf & F & T & C & MC & Mf & F & T & C & M \\
$1961-70$ & 2 & 1 & 2 & 4 & 1 & 3 & 2 & 3 & 1 & 1 & 2 & 1 & 3 & 3 & 1 & 2 & 1 & 4 & 2 & 1 \\
$1971-80$ & 3 & 3 & 4 & 0 & 0 & 2 & 4 & 2 & 2 & 0 & 3 & 5 & 1 & 1 & 0 & 2 & 5 & 1 & 2 & 0 \\
$1981-90$ & 1 & 2 & 0 & 2 & 5 & 1 & 0 & 1 & 3 & 5 & 1 & 0 & 2 & 2 & 5 & 2 & 0 & 1 & 2 & 5 \\
\hline
\end{tabular}

Los Valles Cantábricos son los que anotan menos días de helada. La escasa altitud y sobre todo la presencia próxima del mar Cantábrico impide la presencia de numerosos días de helada (Bilbao-Sondica 13; San Sebastián-Igueldo 9). Resultados algo distintos al periodo internacional anterior (Bilbao-Sondica 11 días de helada al año; San Sebastián- Igueldo 10).

Se ha calculado mediante la recta de tendencia la relación entre la altitud en metros y el periodo libre de heladas, (Gráfico $\mathrm{n}^{\circ}{ }^{2}$ ) resultando que cada cien metros de altitud disminuye el periodo libre de heladas en 13,4 dias $^{3}$. En los Valles Cantábricos y en la Ribera navarra el periodo libre de heladas presenta datos cercanos o superiores a los doscientos días (santesteban 201 dias; Artikutza 209; Olite 195; Sartaguda 194; Buñuel 199), desciende en las Cuencas Intermedias (Pamplona-Observatorio

3 El cálculo se ha realizado a partir de los datos de 17 observatorios. El coeficiente de correlación entre la altitud y el periodo libre de heladas en días es alto $(0,8496)$, y la recta de ajuste presenta la ecuación $y=-0,134 x+235,09$. Datos parecidos a los obtenidos por J. Creus (12 días de reducción cada cien metros de altitud). 


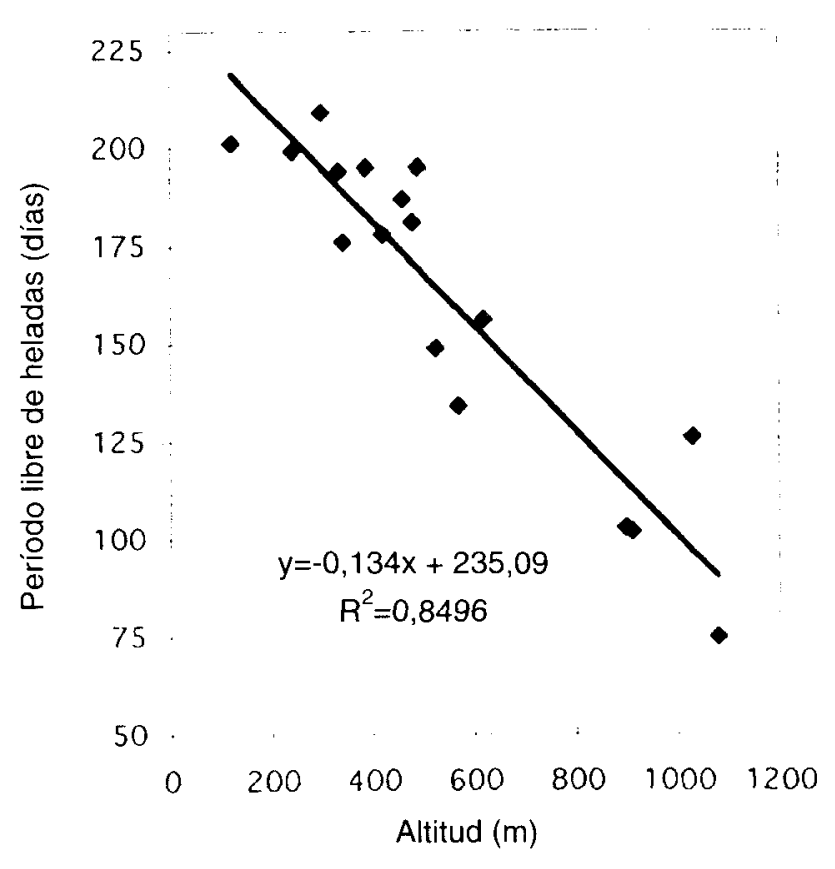

Cuadro 2. Periodo libre de heladas y altitud

187; Alsasua 149) y es más pequeño en los Valles Pirenaicos (Abaurrea Alta 126; Remendia 103; Jaurrieta 102).

El estudio de la amplitud térmica, diferencia entre la temperatura media del más cálido y la del más frío, aporta un dato más para observar los contrastes en el territorio de la transición y ver el grado de continentalidad de cada una de las comarcas. Los Valles Cantábricos anotan la amplitud térmica más baja por su proximidad al mar (Bilbao-sondica $10,9^{\circ}$; San Sebastián-Igueldo $10,8^{\circ}$ ). Dentro de este sector, la altitud y la continentalidad son factores importantes que hacen aumentar en uno o dos grados la

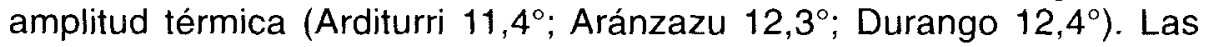
Cuencas Intermedias, más alejadas de los medios marinos, tienen mayor

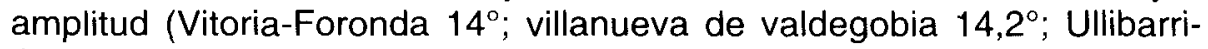
Gamboa 15,2 ; Alsasua $14^{\circ}$; Pamplona-Observatorio 15,3\%). Finalmente el Valle del Ebro obtiene los mayores registros, alcanzando los dieciocho grados en Zaragoza (Logroño-Agoncillo $16,4^{\circ}$; Carcastillo-La Oliva 17, $8^{\circ}$; Zaragoza-Aeropuerto $18,1^{\circ}$ ).

Si se comparan los datos con los del periodo internacional anterior, 1931-60, se observa en los últimos años una disminución de la amplitud 
térmica en los Valles Cantábricos y en las Cuencas Intermedias y un ligero aumento en el Valle del Ebro (Bilbao-Sondica 11, $1^{\circ}$; San SebastiánIgueldo 11,2; Vitoria-Foronda $14,8^{\circ}$; Pamplona-Observatorio $16^{\circ}$; Logroño-Agoncillo $16,3^{\circ}$; Zaragoza-Aeropuerto $17,8^{\circ}$ ).

El índice de continentalidad de Gorczynskit sitúa a los observatorios situados junto al mar cantábrico y a baja altitud dentro del medio oceánico (San Sebastián 6,6; Bilbao 6,8; Arditurri 8,1). Los que se encuentra a mayor altura y algo más al interior están en el limite (Durango 10,8; Aranzazu 10,6). Las Cuencas Intermedias se encuentran dentro del medio continental algo atenuado, aumentando en la Cuenca de Pamplona (Vitoria-Foronda 14,6; Villanueva de Valdegobia 15,7; Ullibarri-Gamboa 16,1; Alsasua 14,6; Pamplona- Observatorio 18,4 $4^{\circ}$. En el valle del Ebro la continentalidad es total, pues se supera el valor veinte (Logroño-Agoncillo 23,7; Zaragoza-Aeropuerto 26,2; carcastillo-la Oliva 24,7).

El índice de oceanidad de Kerner ${ }^{4}$ tiene en cuenta las temperaturas medias de abril y otoño. Los observatorios de los Valles Cantábricos resultan oceánicos con valores superiores a treinta y dentro de los mismos en un alto grado San Sebastián, Bilbao y Aranzazu y en un grado inferior el resto (San Sebastián 41,6; Bilbao 38,5; Arditurri 33,3; Durango 33,6; Aranzazu 39,5). Entre veinte y treinta se sitúan las Cuencas Intermedias con diferencias notables entre los mismos (Vitoria-Foronda 25,7; Villanueva de Valdegobia 21; UllibarriGamboa 29,4; Alsasua 23,6; Pamplona-Observatorio 23,5). El Valle del Ebro anota valores inferiores a veinte que indican ausencia de oceanidad (LogroñoAgoncillo 16,6; Zaragoza-Aeropuerto 14,4; Carcastillo-la Oliva 15,7).

Se ha efectuado el ajuste por el método de los minimos cuadrados y el cálculo de la ecuación de la recta de tendencia sobre las medias móviles de cinco años para ver a qué nivel aumentan o disminuyen las temperaturas medias anuales, conforme los años avanzan, durante el periodo internacional 1961-905.

4 El indice de continentalidad de Gorczynski resulta de aplicar la fórmula $\mathrm{G}=1,7 \times$ Amplitud térmi$\mathrm{ca}$ / seno de la latitud $-20,4$. Si G es inferior a 10 es oceánico y más de 10 continental.

El de oceanidad de Kerner $\mathrm{K}=\mathrm{T}$.oct-T.abril/ amplitud térmica $\times 100$. SiK es mayor a treinta el clima es oceánico.

5 Se trata de la obtención de la linea recta ideal hacia la cual tiende la nube de puntos de un diagrama de dispersión, la fórmula $y=b X+a$. El problema consiste en calcular los parámetros $b$, coeficiente de regresion de y sobre $X$, que expresa la pendiente de la recta o valor que aumenta o disminuye. Esto permite ver cómo la temperaturas medias anuales van a evolucionar en un futuro próximo, en función de los años. Se han calculado las medias móviles de cinco para suavizar las series, ver los distintos periodos existentes con mayor claridad y observar si existen algunas tendencias enmascaradas. Esto supone perder información en los primeros y últimos años de la serie. 
En el observatorio de San Sebastián-Igueldo, la primera década, 196170 , resulta moderadamente cálida por encima de la media, con el año inicial 1961 muy cálido. Hay tres años fríos, que son 1962, 1963 y 1965. La década 1971-80 resulta fria y todos los años se sitúan por debajo de la media. Finalmente el periodo 1981-90 es muy cálido, el más cálido de las tres décadas, y con tendencia claramente ascendente. Los años 1984-86 resultan algo fríos y la serie termina con los dos últimos años muy cálidos. Con estos resultados y considerando la tendencia de las medias móviles de cinco años se produce un incremento medio anual de $0,0104^{\circ}$ a partir de $12,75^{\circ}$, con un coeficiente de correlación muy bajo $(0,1311)$, que explica poco más del diez por ciento de la varianza (gráfico nํㅜㄱ).

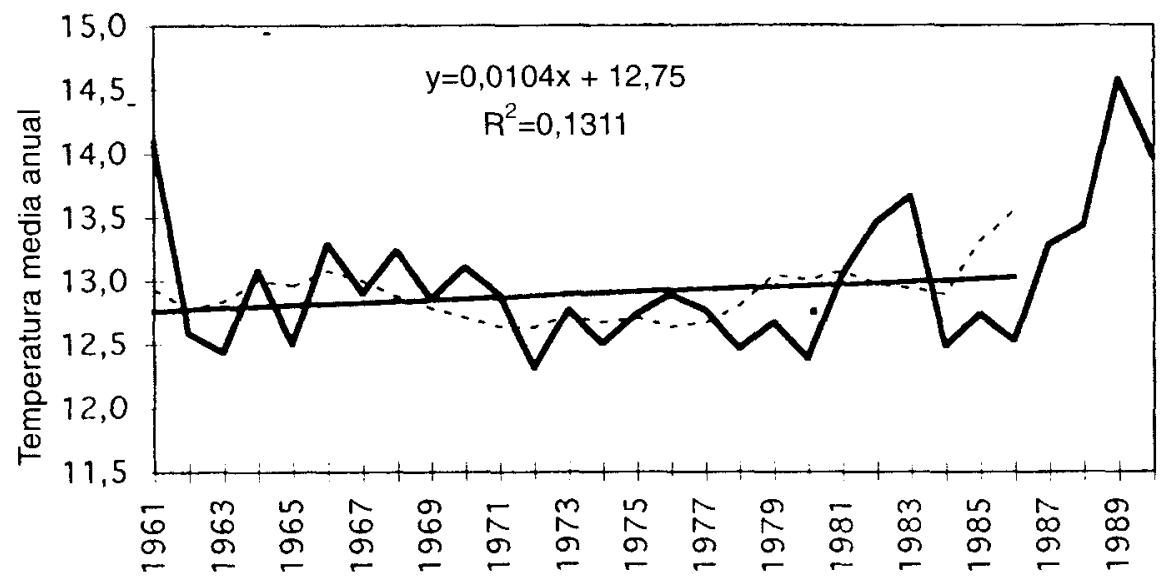

Años 1961-90

Gráfico 3. San Sebastián-Igueldo. Temperaturas medias anuales, medias móviles de cinco años y tendencia lineal (1961-90)

En un estudio anterior se analizaron las series cronológicas de temperaturas medias desde el año 1941 hasta 1997 en los observatorios de Santesteban, Pamplona y Carcastillo-la Oliva (pejenaute Goñi, 1998). Con estas series más amplias se comprobó que los años más cálidos de las series no tienen lugar en los últimos años, sino en las décadas de los cuarenta y cincuenta. Al fragmentar la serie se ha encontrado en el período 1971-1997 una clara correlación de signo creciente en los tres observatorios considerados. En cuanto a la tendencia estacional en los últimos treinta años, la primavera es la estación que está registrando un mayor incremento de las temperaturas en las Cuencas Intermedias y el Valle del 
Ebro, e invierno en los Valles Cantábricos, los veranos registran incrementos más débiles y el otoño tiene un incremento inferior.

En el observatorio de Pamplona, la primera década, 1961-70, resulta ligeramente cálida por encima de la media, con el año inicial 1961 el más cálido de la serie. Dentro de estos años hay dos fríos, que son 1963 y 1965. La década 1971-80 resulta fria y todos los años se sitúan por debajo de la media, salvo 1975 y 1976.

Finalmente el periodo 1981-90 es muy cálido, el más cálido de las tres décadas, y con tendencia claramente ascendente. El año 1984 resulta algo frío y la serie termina con el año 1989 como muy cálido. Con estos resultados y considerando la tendencia de las medias móviles de cinco años se produce un incremento medio anual de $0,0296^{\circ}$ a partir de $11,855^{\circ}$, con un coeficiente de correlación más elevado que explica casi el setenta por ciento de la varianza (gráfico $\mathrm{n}^{\circ} 4$ ).

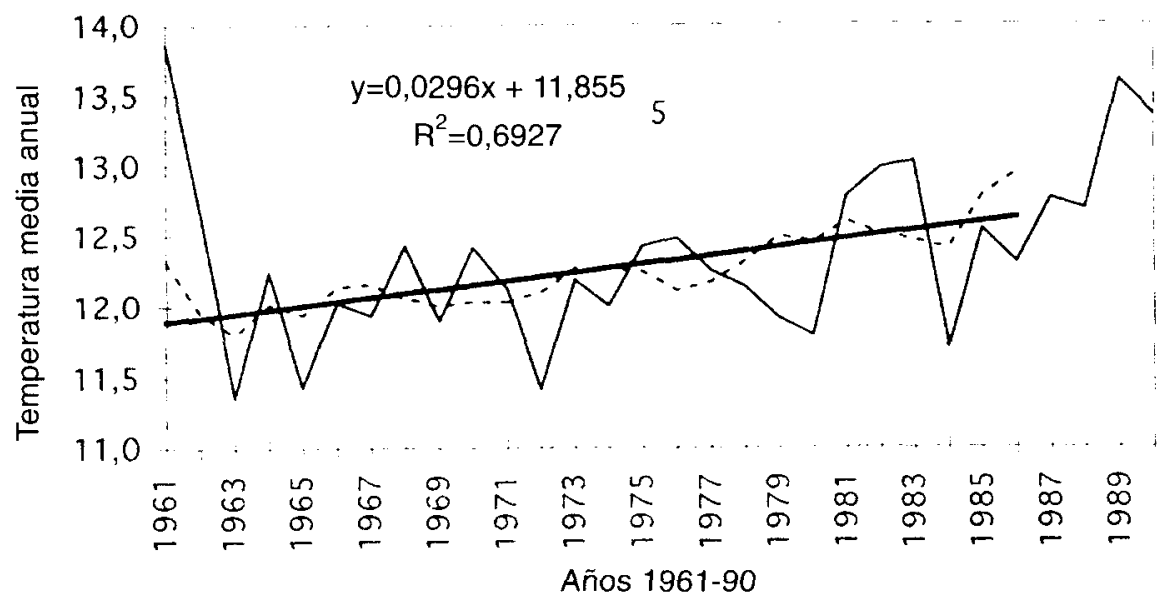

Gráfico 4. Pamplona-Observatorio. Temperaturas medias anuales, medias móviles de cinco años $y$ tendencia lineal (1961-90)

En el obsenvatorio de Zaragoza-Aeropuerto, la primera década, 196170 , resulta moderadamente cálida por encima de la media, con el año inicial 1961 muy cálido, pero superado por el año 1990, último de la serie. Dentro de estos años hay dos fríos, que son 1963 y 1969. La década 1971-80 resulta fria y todos los años se sitúan por debajo de la media. Fi- 
nalmente el periodo 1981-90 es muy cálido, el más cálido de las tres décadas, y con tendencia claramente ascendente. El año 1984 resulta algo frío y la serie termina con los dos últimos años muy cálidos. Con estos resultados y considerando la tendencia de las medias móviles de cinco años se produce un incremento medio anual de $0,041^{\circ}$ a partir de $13,982^{\circ}$, con un coeficiente de correlación medio $(0,5072)$, que explica poco más del cincuenta por ciento de la varianza (gráfico no 5 ).

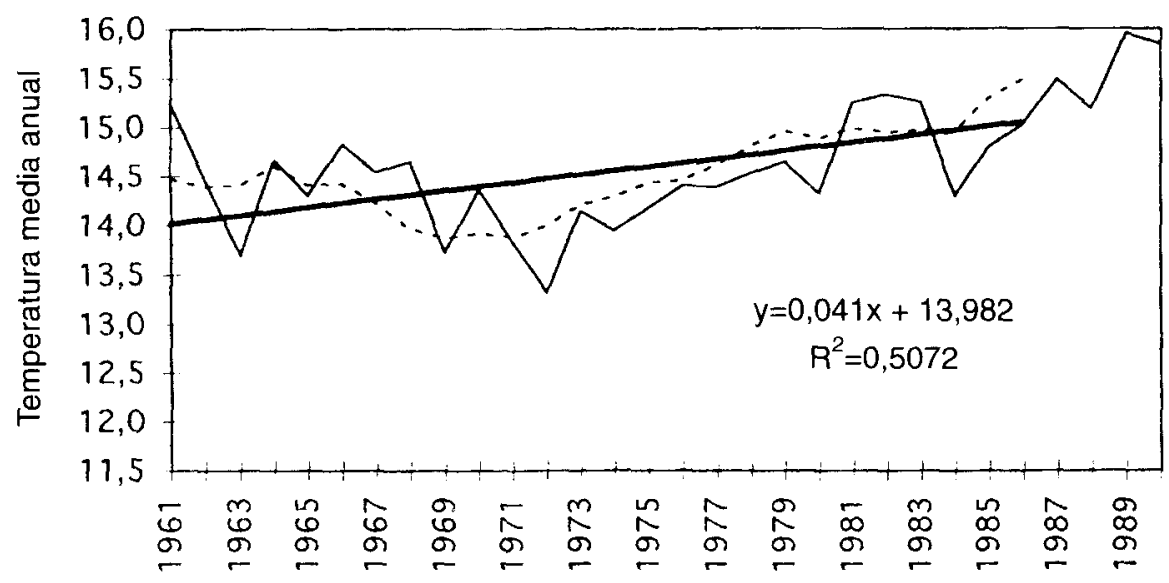

Años 1961-90

Gráfico 5. Zaragoza-Aeropuerto. Temperaturas medias anuales, medias móviles de cinco años y tendencia lineal (1961-90)

\section{CONTRASTES TÉRMICOS ESTACIONALES}

Una vez realizado el estudio anual se pasa al estacional. Para cada estación del año se estudian las temperaturas medias y sus gradientes altitudinales, las medias de las máximas o el grado de calor diurno, las medias de las mínimas o el grado de frío nocturno, las máximas y las mínimas absolutas, el coeficiente de variación, el ritmo de los diferentes meses de cada estación y las heladas y necesidad de calefacción. Para abordar las cuatro estaciones del año se ha elegido el mes más representativo de cada una de ellas (enero para invierno, abril para la primavera, julio para el verano y octubre para el otoño). A partir de estos meses claves se ve el ritmo estacional, comparando sus valores con los otros dos meses de la estación. 


\subsection{El invierno frio}

El invierno es la estación fria del año, pero el grado de frío no es igual en todo el territorio, sino que existen acusadas diferencias entre unos lugares y otros. Este ambiente de frío generalizado es debido, sin duda, a que la incidencia de la actividad solar es minima; durante el dia, las pocas horas de luz solar, apenas bastan para caldear el ambiente, y a la noche, las temperaturas experimentan un enfriamiento considerable, debido a su larga duración. También conviene recordar que en la estación invernal existen diferencias térmicas entre los continentes fríos y los mares más tibios; por eso las comarcas cantábricas próximas al mar gozan de un clima más suave. Asimismo, la dinámica atmosférica también experimenta cambios impqrtantes. Las depresiones de Islandia se ensanchan, siguen trayectorias más meridionales, alcanzan el territorio con más facilidad, y atraen masas de aire frias. Por otra parte, el anticiclón de las Azores, responsable del tiempo seco y soleado, se retira a latitudes más lejanas, y apenas si afecta al territorio.

Si se tiene en cuenta el limite de la temperatura media de $10^{\circ}$ para saber la duración del invierno resulta que en Bilbao y Zaragoza el invierno se extiende desde diciembre a febrero incluidos; en San Sebastián desde diciembre a marzo; en Pamplona y Logroño desde noviembre a marzo; en Vitoria desde noviembre a abril, siempre incluidos; y en Abaurrea Alta (Valles Pirenaicos navarros) desde junio a septiembre.

La temperatura media del mes de enero da a conocer el grado de frío en el mes más crudo de invierno. Muchos dias de enero son claros, luminosos y transparentes, con un cielo de tonalidad azul. Estas jornadas anticiclónicas secas, aunque son dominantes, es raro que persistan a lo largo del mes, como ha sucedido en algunos años secos. Lo más normal es que alternen con dias de lluvia y de nieve. Pero si el anticiclón es potente y supera los 1036 milibares, se agarra con fuerza y puede afectar hasta un mes entero, dando lugar a un tiempo caracterizado por mañanas de heladas, nieblas o escarchas, mediodías suaves y ausencia de lluvias.

Como las distintas comarcas del territorio considerado tienen diferencias en cuanto a la altitud se ha calculado el gradiente térmico vertical de las temperaturas medias de enero, siendo de $0,66^{\circ}$ de disminución cada cien metros de altitud, con un coeficiente de correlación alto $(r 2=0,8993)$. Se pueden distinguir varios sectores en los que el grado de frío incide con distinta intensidad. 
Los Valles Cantábricos son los lugares que obtienen temperaturas medias de enero más altas y se individualizan del resto. La escasa altura y la presencia cercana del mar cantábrico, que atempera las zonas próximas a la costa, son factores que influyen en la presencia del invierno más sua-

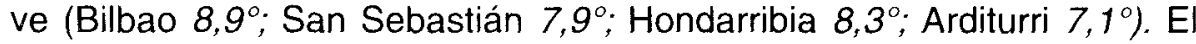
mes de enero resultó ligeramente más suave que el correspondiente al anterior período internacional, 1931-60, (Bilbao-sondica 8, $6^{\circ}$; San Sebastián Igueldo $7,7^{\circ}$ ). Sin embargo dentro de estos valles la uniformidad no es la nota caracteristica y las diferencias aparecen y vienen dadas por la situación más o menos alejadas del mar y la altitud (Durango 6,5 ; Aranzazu $5,1^{\circ}$; Artikutza $6,8^{\circ}$ ). Los observatorios situados junto a la costa y a poca altitud registran temperaturas medias de invierno más elevadas.

El Valle del Ebro, con valores térmicos entre cuatro y seis grados de temperatura media de enero, es el sector menos frío después de los Valles Cantábricos. La continentalidad afecta a las comarcas del Ebro, Ribera y Navarra Media, en el corazón del invierno que, alejadas de los medios marinos, se caracterizan por los extremos: de dia la temperatura sube en las horas centrales del día y de noche el enfriamiento por irradiación es intenso, dando lugar a descensos térmicos e importantes heladas. El alto Valle del Ebro es algo más frío que el bajo Valle del Ebro (Logroño-Agoncillo 5.8 $8^{\circ}$; Zaragoza-Aeropuerto $6,2^{\circ}$ ). Temperaturas de enero ligeramente inferiores a las del periodo internacional 1931-60 (Logroño-Agoncillo 5, $6^{\circ}$; Zaragoza-Aeropuerto $6,1^{\circ}$ en ambos casos).

Entre los dos sectores anteriores, el oceánico y mediterráneo, se encuentran el territorio de la transición, formado por las las Cuencas Intermedias que presentan cifras inferiores a los anteriores y por lo tanto ugares de mayor frío. Se trata de cuencas cerradas y por encima de los cuatrocientos metros, bastante frias en invierno y favorables a la presencia de inversiones térmicas y heladas. La Cuenca de Pamplona es menos fria que la Llanada de Vitoria y el Corredor del Arakil (Pamplona-Observatorio $5,2^{\circ}$; Vitoria-Foronda $4,5^{\circ}$; Ullivarri-Gamboa $3,9^{\circ}$; Villanueva de Valdegovia $4,5^{\circ}$; Alsasua $4,4^{\circ}$ ). Temperaturas de enero ligeramente superures a ias del periodo internacional 1931-60 en Pamplona y similares en Vitoria (Vitoria-Instituto 4,5 ; Pamplona-Obsenvatorio 4,6 $6^{\circ}$.

Pero donde el rigor de frío se deja sentir con mayor intensidad es en los Valles Pirenaicos, zona que por su elevada altura y mayor continentalidad registra las temperaturas medias de enero más bajas de Navarra (Abaurrea Alta $1,5^{\circ}$ ). Existe una diversidad grande en este sector, pero con el denominador común de ambiente muy frío, con la única excepción 
de la zona de valcarlos, que, abierta a las influencias del cantábrico, presenta valores suaves parecidos a los de los más suaves de los Valles Cantábricos. Salvada esta excepción, el clima de enero es riguroso en la zona. Los valles de Salazar y Roncal tienen temperaturas bajas que indican frío intenso en invierno. Las temperaturas descienden con la altura, siendo el frío muy intenso en los lugares elevados.

Existen diferencias importantes entre unos eneros y otros en cuanto a las temperaturas medias. El enero más frío en San-Sebastián-Igueldo y Pamplona-Observatorio fue $1985\left(4,1^{\circ}\right.$ Y $1,8^{\circ}$ respectivamente) y 1964 en Zaragoza-Aeropqerto $\left(3,1^{\circ}\right)$ y el más cálido 1982 en los tres observatorios $\left(10,6^{\circ} ; 8,6^{\circ} ; Y 9,4^{\circ}\right.$.respectivamente), por lo que .el recorrido supera los seis grados en los tres observator10s (San Sebastián-Igueldo de 6,1 ${ }^{\circ}$; Pamplona-Observatorio $6,8^{\circ}$; Zaragoza-Aeropuerto $6,3^{\circ}$ ).

El coeficiente de variación que nos permite comparar la dispersión de las temperaturas medias de enero, es inferior en los Valles Cantábricos y Valle del Ebro (San Sebastián- Igueldo 19\%; Santesteban 21\%; LogroñoAgoncillo 25\%; Zaragoza-Aeropuerto 24\%), aumenta en las Cuencas Intermedias (Vitoria-Foronda 35\%; Pamplona-Observatorio $30 \%$ ) y se dispara en los Valles Pirenaicos.

El ritmo estacional entre los tres meses de invierno, que se puede apreciar con la observación de la diferencia en grados entre la temperatura de enero con la de los otros dos meses de invierno, nos ayuda a ver cómo es el ascenso y descenso térmico, o sea si hay o no recuperación en las temperaturas y si se está saliendo o no del pozo invernal. El descenso térmico de diciembre con respecto a enero es muy pequeño, oscila entre $0,3^{\circ}$ de Zaragoza-Aeropuerto y $0,7^{\circ}$ de San Sebastián-Igueldo, salvo en los Valles Pirenaicos en que supera el grado (Abaurrea Alta $1,3^{\circ}$ ).

El ascenso térmico de febrero con respecto a enero es más alto en las Cuencas Intermedias (Pamplona-Observatorio $1,2^{\circ}$ ) y en el Valle del Ebro (Zaragoza-Aeropuerto $1,8^{\circ}$ ) y se mantiene al mismo ritmo en los Valles Cantábricos (San Sebastián-Igueldo $0,6^{\circ}$ ). Este mes es desconcertante en todo el territorio, pues alternan días despejados de atmósfera transparente y calor en las horas centrales del dia, con jornadas frias, originadas por anticiclones que trasladan por sus extremos aire frío septentrional.

Varias son las situaciones atmosféricas que dan lugar a tiempos fríos de invierno. Las del norte y noreste, formadas por una dorsal que se extiende por el Atlántico con orientación meridiana hasta Islandia y una borrasca en el Golfo de León o de Génova, trasladan masas de aire polares 
o árticas que dan lugar a días muy fríos. Algunos anticiclones invernales, como los que se centran en las Islas Británicas, y que por su flanco oriental atraen aire polar continental frío, acompañado de viento cierzo en superficie, dan días con temperaturas bajas, sobre todo a las mañanas.

Las temperaturas medias de las máximas de enero señalan el grado de calor diurno en enero. El invierno no supone en este territorio un ambiente de frio continuo, sino que en algunas ocasiones con jornadas soleadas las temperaturas se moderan al mediodia y primeras horas de la tarde. Con anticiclones cálidos, ausencia de nieblas persistentes y estancamiento de masas de aire moderadas, hay un calentamiento, que propicia la presencia de calor moderado al mediodia. Los Valles Cantábricos son los que mayor calor registran en las horas centrales del dia, debido a la escasa altitud en que se encuentran y a la influencia próxima del mar cantábrico, que supone una suavización en las temperaturas máximas, que varian con la altitud y la proximidad al mar (Bilbao-Sondica 12,9 $9^{\circ}$ San Sebastián-

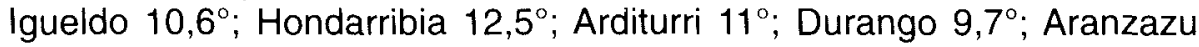
$\left.7,3^{\circ}\right)$. Temperaturas algo superiores con respecto al periodo internacional anterior, 1931-60 (Bilbao- Sondica 12,1 ${ }^{\circ}$; San Sebastián-Igueldo 10,2 ${ }^{\circ}$.

El Valle del Ebro tiene una temperatura media de las máximas de enero inferior a la de los Valles Cantábricos, pero con escasas diferencias (Logroño-Agoncillo 9,3; Zaragoza-Aeropuerto 10,1 $1^{\circ}$ ) Temperaturas dos décimas superiores con respecto al periodo internacional anterior, 193160 (Logroño-Agoncillo 9,1 ${ }^{\circ}$; Zaragoza-Aeropuerto 9,9 ${ }^{\circ}$ ). En las Cuencas Intermedias el grado de calor diurno es inferior al de los sectores anteriores. La Cuenca de Pamplona es algo más templada en invierno que la Llanada de Vitoria y ambas superan al Corredor del Arakil que resulta más frío (Vitoria-Foronda $8,1^{\circ}$; Pamplona-observatorio $8,7^{\circ}$ ) temperaturas algo superiores con respecto al periodo internacional anterior, 1931-60 (Vitoria-Foronda $7,8^{\circ}$; Pamplona-observatorio $8,5^{\circ}$ ). El grado de calor de enero es inferior en los Valles Pirenaicos (Abaurrea Alta $6^{\circ}$ ).

Pese al menor caldeamiento producido por la inferior intensidad de los rayos solares y las pocas horas de sol en enero, los observatorios son susceptibles, en algunas ocasiones, de alcanzar temperaturas máximas elevadas, como lo demuestran las temperaturas máximas absolutas de enero que se sitúan entre los diecisiete y los veintidós grados en todo el territorio, salvo en los Valles Pirenaicos y otras áreas montañosas (Bil-

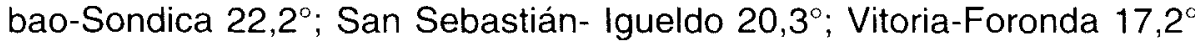
Pamplona-Observatorio $18,2^{\circ}$; Logroño-Agoncillo $18^{\circ}$; Zaragoza-Aeropuerto $19^{\circ}$; Abaurrea Alta $14^{\circ}$ ). 
Las temperaturas máximas altas se suelen dar con el llamado tiempo cálido de invierno, que tiene lugar cuando un anticiclón se encuentra centrado en el mar Mediterráneo y una lengua cálida se extiende desde el Norte de Africa hasta el Sur de Europa y llegan masas de aire suaves, porque proceden del Atlántico sur y, además, se han ido recalentando al atravesar las sucesivas cadenas peninsulares.

Otra de las caracteristicas que definen la estación invernal es el frío nocturno en las largas noches de invierno, hecho que se desprende del estudio de las temperaturas medias de las mínimas de enero. Los Valles Cantábricos son los que en menor grado acusan el rigor de las noches invernales y obtienen los registros más altos del territorio, próximos a los cinco grados (Bilbao-Sondica 4,8 $8^{\circ}$; San Sebastián-Igueldo 5,3 ). Temperaturas ligeramente superiores en San Sebastián al periodo internacional anterior 1931-60 e inferior al de Bilbao (Bilbao-Sondica $5^{\circ}$; San Sebastián-igueldo $5,1^{\circ}$ ). Los observatorios situados a mayor altitud y alejados del mar obtienen registros más bajos (Durango $3,3^{\circ}$; Aranzazu $2,9^{\circ} ;$ Arditurri $3,2^{\circ}$ ).

El Valle del Ebro obtiene resultados inferiores a los Valles Cantábricos, entre dos y tres grados (Logroño-Agoncillo 2,2 $2^{\circ}$; Zaragoza-Aeropuerto $2,3^{\circ}$ ). Valores casi similares a los del periodo internacional anterior (Logroño-Agoncillo $2,1^{\circ}$; Zaragoza-Aeropuerto. $2,3^{\circ}$ ). Las características de la Cuenca del Ebro, especie de depresión continental, ayuda además a que el aire frío, más pesado, se embolse en las zonas bajas a lo largo de la noche. Las Cuencas Intermedias registran valores inferiores a los obtenidos en el Valle del Ebro, por lo que el ambiente de frio nocturno es mayor. La Llanada de Vitoria y el Corredor del Araki son más fríos que las Cuencas de Pamplona y Lumbier-Aóiz (Vitoria-Foronda $1^{\circ}$; Villanueva de Valdegovia - $0,1^{\circ}$; Ulibarri-Gamboa $0,6^{\circ}$; Pamplona-Observatorio $1,8^{\circ}$ ). Registros distintos a los del período internacional 1931-60 (Vitoria-Foronda $1,3^{\circ}$; Pamplona-Observatorio $0,7^{\circ}$ ).

Finalmente, en los Valles Pirenaicos es donde con mayor intensidad se deja sentir el frío nocturno, dando lugar a noches gélidas durante el invierno, intensificadas por la presencia cercana de la nieve. En los pueblos de los pirineos las noches de invierno son crudas, debido a la altura, a la continentalidad mayor o menor según los casos y a la menor insolación, por ser valles encajonados entre altas montañas ( Abaurrea Alta $-0,9^{\circ}$ )

Las temperaturas mínimas absolutas obtenidas en los observatorios del territorio dejan ver el ambiente frío extraordinario que pueden alcan- 
zar los distintos sectores de la Transición. Con olas de frío hasta los lugares más templados en invierno, como son los Valles Cantábricos, pueden obtener registros bajos (Bilbao-Sondica $-8,6^{\circ}$; San Sebastián-Igue1do $-10^{\circ}$ ). El Valle del Ebro anota mínimas absolutas por debajo de los diez grados bajo cero (Logroño- Agonci110 -11, $6^{\circ}$; Zaragoza-Aeropuerto $-11,4^{\circ}$ ) y las Cuencas Intermedias rebasan la cifra de los quince grados bajo cero (Vitoria-Foronda $-17,8^{\circ}$; Pamplona-Observatorio $\left.-16,2^{\circ}\right)$. En los Valles Pirenaicos el grado de frío nocturno alcanza altas cotas, propias de un medio de montaña (Abaurrea Alta - $18^{\circ}$ ). Estos registros tan bajos se obtuvieron en las olas de frío de invierno que aparecen en algunas ocasiones y que dejan al territorio sumido en un mar de frío invernal. Los ejemplos más claros y recientes tuvieron lugar en febrero de 1983 y en enero de 1985.

El número medio de días de helada en los tres meses de invierno da una idea más completa del frío invernal en las comarcas navarras. Los Valles Pirenaicos y las altas montañas del territorio registran alrededor de sesenta días de helada, es decir casi las dos terceras partes de los días de invierno tienen helada. Algunos lugares del Valle del Ebro, son muy fríos y registran cifras cercanas, e incluso superiores a los cuarenta dias de helada, es decir aproximadamente la mitad de las jornadas de la estación inviernal tienen heladas (Olite 35 dias de helada; carcasti110 43; Yesa 37). Las Cuencas Intermedias anotan cifras aproximadas a treinta días de helada, es decir dos terceras partes de los dias de invierno tienen heladas (Vitoria-Foronda y Pamplona-Observatorio 31 días). El Valle del Ebro registra unos veinte días de helada, menos que en los sectores anteriores (Logroño-Agoncillo 19,2; Zaragoza- Aeropuerto 22,2). Los Valles Cantábricos son los que tienen menos días de helada (Bilbao-Sondica 9,6; San Sebastián- Igueldo 7,1). Estos resultados son algo superiores a los del período internacional anterior (Vitoria-Foronda 28,9; Pamplona-Observatorio 27 dias de helada; Logroño-Agoncillo 19,5; Zaragoza-Aeropuerto 17,2; Bilbao-Sondica 8,5; San Sebastián-Igueldo 9,7).

Los contrastes en cuanto a los días de helada se ponen de manifiesto al analizar otros datos, como la necesidad de calefacción en grados día, que aunque es un indice no exacto del todo 6 permite establecer diferencias en cuanto al consumo de calefacción entre los observatorios de la

6 Se ha calculado aplicando $G C=i(15-t d)$, en donde $G C$ son los grados-día de calefacción y td la temperatura media del mes (Fernández Garcia, 1995). Tiene el inconveniente de que no tiene en cuenta el viento, que es un factor influye mucho, y además, los datos hay que obtener los con las temperaturas medias mensuales, al no poseer los datos de temperaturas medias diarias. y otros tales como las condiciones térmicas de los edifcios y sus cerramientos. 
Transición. Los Valles Cantábricos son los que menos necesidad de calefacción tienen en invierno con resultados entro los quinientos y setecientos grados, siendo inferiores en Bilbao (Bilbao-Sondica 519; San Sebastián-Igueldo 600; Santesteban 647). La necesidad de calefacción aumenta en Zaragoza y Logroño (732 y 770 respectivamente).

Las Cuencas Intermedias tienen necesidades de calefacción distintas según las zonas: La Cuenca de Pamplona es más suave que la Llanada de Vitoria y el Corredor del Arakil el más frío. En algunos de estos lugares la necesidad de calefacción es casi el doble que en Bilbao (Alsasua 908; Vitoria-Foronda 890; Pamplona-Observatorio 832). En los Valles Pirenaicos el indice se dispara (Abaurrea Alta 1153)

\subsection{Una primavera desconcertante}

La primavera, periodo de tránsito entre el invierno frío y el verano cálido, no tiene lugar de un modo brusco, sino que se van sucediendo tipos de tiempo rigurosos y moderados, secos y lluviosos, sin un orden y de una manera, muchas veces desconcertante. Ahora bien, la mayor insolación se nota cada vez más en las temperaturas más suaves, que suponen una salida del pozo invernal. Las diferencias de temperaturas entre los continentes y los océanos son inferiores, la corriente en altura se torna más lenta y aparece una circulación ondulada que atraviesa el territorio, dando lugar a días cálidos y secos al paso de los anticiclones atlánticos y a jornadas lluviosas al paso de los temporales de lluvias; todo esto sucede, a veces, en un corto espacio de tiempo.

Si se tiene en cuenta el limite de la temperatura media de 100 para saber la duración del invierno, resulta que en Bilbao y Zaragoza el invierno no abarcaria ningún mes de primavera; marzo seria un mes de invierno en San Sebastián, Pamplona y Logroño; y en Vitoria y en Abaurrea Alta (Valles Pirenaicos navarros) se tendria que incluir a abril.

Del estudio de las temperaturas medias de abril, mes tipicamente primaveral, se observa los contrastes existentes en nuestro territorio. Como las distintas comarcas del territorio considerado tienen diferencias en cuanto a la altitud se ha calculado el gradiente térmico vertical de las temperaturas medias de abril, siendo de $0,68^{\circ}$ de disminución cada cien metros de altitud a partir de 13,50 de temperatura, con un coeficiente de correlación alto $\left(\mathrm{r}^{2}=0,7755\right)$. 
El Valle del Ebro y los Valles Cantábricos más caldeados, situados cerca del mar y a baja altitud, son los más cálidos con temperaturas próximas o algo superiores a los doce grados de temperatura media del mes de abril. (Bilbao $11,8^{\circ}$; Hondarribia $12,1^{\circ}$; Zaragoza-Aeropuerto $12,8^{\circ}$; LogroñoAgoncillo $11,5^{\circ}$ ). Resultados inferiores, sobre todo en Zaragoza, a los del periodo internacional 1931-60 (Zaragoza-Aeropuerto 13,7 ; Logroño-Agoncillo $11,8^{\circ}$; Bilbao- Sondica $12,1^{\circ}$ ). Se puede afirmar que el invierno ha quedado superado, si bien conviene matizar que estos lugares no están exentos de irrupciones frías que provocan un ambiente frío general. Los valles guipuzcoanos y vizcainos situados a cierta altura, se caracterizan por una mayor moderación (Arditurri 10,6 $6^{\circ}$; Durango 9,8 $8^{\circ}$; Aranzazu $8^{\circ}$ )

Abril resulta más frío en las Cuencas Intermedias. La Cuenca de Pamplona es más cálida que la Llanada de Vitoria y el Corredor del Arakil (Vitoria-Foronda $9,2^{\circ}$; Villanueva de Valdegovia $9,3^{\circ}$; Ullibarri-Gamboa $8,6^{\circ}$; Alsasua $9,1^{\circ}$; Pamplona-Obsenvatorio $10,3^{\circ}$ ). Estos resultados son inferiores a los registrados en el periodo internacional 1931-60 (Vitoria-Foronda $10,4^{\circ}$; Pamplona-Observatorio $11,1^{\circ}$ ). Los anticiclones dan lugar a temperaturas más suaves, teniendo lugar una recuperación notable con respecto al mes de marzo. El Corredor del Arakil está más expuesto a las situaciones frias por ser un pasillo cerrado entre las sierras de Aralar y Urbasa. Abril sigue siendo un mes de invierno en los Valles Pirenaicos (Abaurrea Alta $5,6^{\circ}$ ), si' bien puede haber jornadas con temperaturas cálidas al mediodía .

Existen diferencias importantes entre unos abriles y otros, si se observan las temperaturas medias del periodo. El abril de 1986 fue el más frío en san-Sebastián-Igueldo, Pamplona-Obsenvatorio, Zaragoza-Aeropuerto y Abaurrea Alta $\left(7,3^{\circ} ; 6,8^{\circ} ; 10,4^{\circ}\right.$ y $1,4^{\circ}$ respectivamente) y el de $1987 \mathrm{el}$ más cálido en San Sebastián-Igueldo, Zaragoza-Aeropuerto y Abaurrea Alta y 1961 en Pamplona-Obsenvatorio $\left(13,5^{\circ} ; 15,3^{\circ} ; 8,7^{\circ} \mathrm{Y} 13,4^{\circ}\right.$ respectivamente), por lo que el recorrido supera los seis grados en San Sebastián y Pamplona y alcanza los cinco en Zaragoza (San Sebastián-Igueldo de $6,2^{\circ}$; Pamplona-Observatorio $6,6^{\circ}$; Zaragoza-Aeropuerto $4,9^{\circ}$ ).

El coeficiente de variación, que nos permite comparar la dispersión de las temperaturas medias de abril, es inferior con respecto al de enero en todos los observatorios. Es más bajo en el Valle del Ebro, sobre todo en Zaragoza (Logroño-Agoncillo 11\%; Zaragoza 8\%); aumenta en los Valles Cantábricos y en las Cuencas Intermedias (San Sebastián-Igueldo 13\%; Santesteban 13\%; Vitoria-Foronda 14\%; Pamplona-Observatorio 14\%) y se dispara en los Valles Pirenaicos (Abaurrea Alta 26\%). 
El ritmo estacional entre los tres meses de primavera, se puede apreciar con la observación de la diferencia en grados entre la temperatura de abril con la de los otros dos meses de primavera. Marzo es todavia un mes frío de invierno y el ascenso térmico con respecto al mes de febrero es de uno o dos grados, con aumento de norte a sur, por lo tanto menos significativo en los Valles Cantábricos y más en el Valle del Ebro (San Sebastián-Igueldo $0,9^{\circ}$; Abaurrea Alta 1,2 ; Pamplona-Observatorio 1,8 ; Zaragoza $2,2^{\circ}$ ).

El ascenso térmico de abril con respecto a marzo es más pronunciado; oscila entre uno y tres grados y presenta un aumento de norte a sur, es decir más suave los Valles Cantábricos y más pronunciado en el Valle del Ebro (San Sebastián-Igueldo $1,3^{\circ}$; Abaurrea Alta 2,3 $3^{\circ}$; Pamplona- Observatorio $1,9^{\circ}$; Zaragoza-Aeropuerto $2,6^{\circ}$ )

Mayo es un mes de primavera asentada en el que las temperaturas registran valores altos que suponen una superación de los fríos invernales y en algunos lugares anuncian la llegada de las caracteristicas estivales. El ascenso térmico con respecto al mes de abril, que oscila entre tres y cuatro grados, es elevado en todo el territorio, lo que nos hace pensar en la superación del invierno y en la presencia de temperaturas moderadas propias de primavera (San Sebastián-Igueldo 2,8 $8^{\circ}$; Abaurrea Alta $4^{\circ}$; Pamplona-Observatorio $3,6^{\circ}$; Zaragoza-Aeropuerto $4^{\circ}$ )

Los diferentes valores de temperatura media de las máximas de abril en el territorio de la Transición, nos dan una idea del grado de calor que alcanza este mes en las horas centrales del dia. El Valle del Ebro resulta el lugar más cálido (Zaragoza-Aeropuerto $18,3^{\circ}$; Logroño-Agoncillo 16,4; BilbaoSondica $16,4^{\circ}$; Hondarribia $\left.16,3^{\circ}\right)$. Resultados inferiores a los del periodo internacional anterior, 1931- 60, sobre todo los del Valle del Ebro (Zaragoza-Aeropuerto 19,3 $3^{\circ}$; Logroño-Agoncillo $17,2^{\circ}$; Bilbao-Sondica $16,9^{\circ}$ ).

El grado de calor es inferior en las Cuencas Intermedias y en los Valles Cantábricos, situados por encima de los trescientos metros. La Cuenca de Pamplona tiene mayor grado de calor al mediodia que San Sebastián y Vitoria, y parecido a otros observatorios de los Valles Cantábricos (Pamplona-Observatorio 14,9 ${ }^{\circ}$; Durango $14,4^{\circ}$; Arditurri 15 ${ }^{\circ}$; San Sebastián-Igueldo $13,8^{\circ}$; Vitoria-Foronda $13,9^{\circ}$; Ullivarri- Gamboa $13,2^{\circ}$ ). Los observatorios de montaña de los Valles Cantábricos resultan más fríos (Aranzazu $11^{\circ}$ ). Resultados inferiores a los anotados en el periodo internacional 1931- 60 (Pamplona-Observatorio 16,3; San Sebastián-Igueldo $14,8^{\circ}$. Vitoria-Foronda $15,4^{\circ}$ ). Los Valles Pirenaicos registran los valores 
más bajos del territorio, pues resultan poco calurosos, incluso al mediodia, debido a la altitud en que se encuentran (Abaurrea Alta $8,6^{\circ}$ ). Aqui el invierno sigue presente y el calor todavia asoma con escasa nitidez en las primeras horas de la tarde.

Los observatorios son susceptibles, en algunas ocasiones, de alcanzar temperaturas máximas importantes: así lo demuestran las temperaturas máximas absolutas de abril que se sitúan entre los veinticinco y los treinta grados en todo el territorio, salvo en los Valles Pirenaicos y otras áreas montañosas más frías (Bilbao-Sondica 31,2 ; San Sebastián-Igueldo 27,4 $4^{\circ}$; Vitoria-Foronda 25,4 Pamplona- Observatorio 26,6 ${ }^{\circ}$; LogroñoAgoncillo 27, $2^{\circ}$; Zaragoza- Aeropuerto 29,4; ; Abaurrea Alta $22^{\circ}$ ).

La temperatura media de las mínimas de abril muestra el grado de frío nocturno. Los Valles Cantábricos situados casi al nivel del mar y el bajo Valle del Ebro son los sectores más moderados de Navarra, que alcanzan los siete grados (San Sebastián-Igueldo $7,5^{\circ}$; Hondarribia 7,9 $9^{\circ}$; Zaragoza-Aeropuerto $\left.7,2^{\circ}\right)$. Los observatorios situados a cierta altura registran valores térmicos más débiles (Arditurri $6,2^{\circ}$; Durango $5,3^{\circ}$; Aranzazu $5^{\circ}$ ). El alto Valle del Ebro tiene registros algo inferiores (Logroño-Agoncillo 6,6 $6^{\circ}$ ). Las Cuencas Intermedias tienen noches más frías, debido a ser cuencas cerradas rodeadas de montañas (Vitoria-Foronda 4,5 $5^{\circ}$ Pamplona-Observatorio $5,7^{\circ}$; Villanueva de Valdegovia $2,5^{\circ}$; Ullivarri-Gamboa $4,1^{\circ}$ ). Los Valles Pirenaicos, tienen noches muy frias. Las temperaturas mínimas son inferiores a un grado a las del período internacional, 1931-60, en San Sebastián, Vitoria y Zaragoza, y muy parecidas en Bilbao, Logroño y Pamplona.

Las temperaturas mínimas absolutas señalan el ambiente frío que pueden alcanzar los distintos sectores de la transición en abril. En todos los lugares se ha registrado temperaturas por debajo de los cero grados. En las Cuencas Intermedias y en el Valle del Ebro se ha llegado a los dos bajo cero y en los Valles Pirenaicos a los seis bajo cero (Bilbao-Sondica $0,8^{\circ}$; San Sebastián-Igueldo $-0,4^{\circ}$; Logroño- Agoncillo $-2^{\circ}$; Zaragoza-Aeropuerto $-2,4^{\circ}$; Vitoria-Foronda - $3,2^{\circ}$; Pamplona-Observatorio $-2,8^{\circ}$; Abaurrea Alta $-6^{\circ}$ )

Las heladas de primavera son muy inferiores a las del invierno, pero en algunas comarcas todavía están presentes. El número medio de días de helada de primavera es bajo en el Valle del Ebro y en los Valles Cantábricos (Logroño- Agoncillo 2,2 días de helada; Zaragoza-Aeropuerto 2,7; Bilbao-Sondica 2,4; Hondarribia 1,7), aumenta en las Cuencas Intermedias, en donde pueden alcanzar e incluso superar los diez días, como sucede 
en la Llanada de Vitoria y en el Corredor del Arakil (Vitoria-Foronda 10,5; Pamplona- Observatorio 8, Alsasua 11,8). En los Valles Pirenaicos las cifras aumentan considerablemente anotando treinta y cinco días de helada en los observatorios más altos (Abaurrea Alta 35,2 días de helada).

La última fecha de heladas varia según las diferentes zonas de Navarra. En los Valles Pirenaicos se retrasa hasta bien entrado mayo (Abaurrea Alta 26 de mayo fecha extrema de última helada). En los Valles Cantábricos se sitúa a mediados del mes de abril, no habiéndose anotado ninguna helada con posterioridad a esta fecha en los años que se han estudiado. En las Cuencas Intermedias se prolonga hasta últimos de abril o primeros de mayo y se retrasa algo más en el Corredor del Arakil (Pamplona-Observatorio 24 de abril; Alsasua 19 de mayo). En Navarra Media se prolonga a últimos de abril, si bien en algunos lugares se retrasa hasta mediados de mayo. En la Ribera tiene lugar en la segunda quincena de abril (Fitero 25 de abril; Carcastillo-La Oliva 29 de abril) y estos contrastes en cuanto a los días de helada se ponen de manifiesto al analizar la necesidad de calefacción en grados día en primavera, que permite establecer diferencias en cuanto al consumo de calefacción entre los distintos observatorios. Los Valles Cantábricos y el Valle del Ebro son los que menos necesidad de calefacción tienen en primavera con resultados que se sitúan entre los doscientos y trescientos grados, siendo inferiores en Zaragoza y Bilbao y algo más elevados en San Sebastián (Bilbao-Sondica 251; San SebastiánIgueldo 349; Santesteban 245; Zaragoza 215; Logroño 282). Las Cuencas Intermedias tienen necesidades de calefacción distintas según las zonas: La Cuenca de Pamplona es más suave que la Llanada de Vitoria y el Corredor del Arakil el más frío. En estos lugares la necesidad de calefacción llega a ser en algunos lugares el doble que en Bilbao (Alsasua 512; VitoriaForonda 493; Pamplona-Observatorio 386). En los Valles Pirenaicos el índice alcanza valores muy altos (Abaurrea Alta 800).

\subsection{Los veranos suaves de los Valles Cantábricos y cálidos del Valle del Ebro}

El estío se caracteriza por la presencia de tiempos calurosos y secos que se suceden de un modo monótono, solamente interrumpido por la formación de núcleos tormentosos o la llegada de aire frío del norte, alivio térmico, que refresca el ambiente. En verano se suceden los días más largos del año y las masas de aire cálidas estancadas en nuestro territorio en condiciones anticiclónicas, con apenas intercambio de aire, cada día que pasa, se van calentado más. 
También la dinámica atmosférica experimenta cambios en la época estival. La circulación del oeste, que traía en primavera abundantes lluvias, se retira hacia latitudes más altas y el anticiclón de las Azores, más poderoso ahora, se extiende por la península Ibérica. Además en altura la corriente del chorro polar se encuentra alejada y debilitada, y sobre nuestra vertical aparecen crestas anticiclónicas, responsables del ambiente seco de verano. Sin embargo, puede ocurrir que los anticiclones subtropicales en altura, dominantes en esta época, desaparezcan y sean sustituidos por vaguada s o depresiones frías. si esto suc.ede, se producen fuertes ascensiones que dan lugar a la aparición de tormentas estivales, que llegan siguiendo direcciones muchas veces caprichosas.

Se va a tener en cuenta el umbral de temperatura media de $20^{\circ}$ y $18^{\circ}$ para saber el tipo de verano que tienen los diversos sectores de la Transición. Según estos parámetros, el bajo Valle del Ebro es el más cálido con cuatro meses que superan los veinte grados. Veranos algo menos cálidos se dan en el alto Valle del Ebro (Navarra Media y Ribera), Cuenca de Pamplona y Valles Cantábricos más soleados y situados a baja altitud (santesteban, Hondarribia) que se caracterizan por tener julio y agosto por encima de veintidós grados y junio y septiembre por encima de los dieciocho grados. Los veranos templados aparecen en el Corredor del Arakil, la Llanada de Vitoria y la mayor parte de los Valles Cantábricos que no tienen ningún mes por encima de los veinte grados y julio y agosto superan lo dieciocho grados. Finalmente las zonas montañosas, especialmente los Valles Pirenaicos, tienen un verano muy fresco, dado que ningún mes llega a los dieciocho grados.

Las temperaturas medias de julio señalan las caracteristicas térmicas en el mes más cálido del estio. Como las distintas comarcas del territorio considerado tienen diferencias en cuanto a la altitud se ha calculado el gradiente térmico vertical de las temperaturas medias de julio, siendo de $0,58^{\circ}$ de disminución cada cien metros de altitud a partir de $22,9^{\circ}$ de temperatura, con un coeficiente de correlación algo bajo $\left(r^{2}=0,4042\right)$.

El Valle del Ebro es el sector más cálido en julio con temperaturas medias por encima de veintidós grados, de los que sobresalen los observatorios del bajo Valle del Ebro que alcanzan los veinticuatro grados (Zaragoza 24,3 ${ }^{\circ}$; Logroño- Agoncillo 22, $2^{\circ}$, Carcastillo-la Oliva $22,6^{\circ}$; Fitero $22,1^{\circ}$; Yesa $22,3^{\circ}$ ). Resultados algo superiores a los registrados en el periodo internacional 1931-60 (Zaragoza-Aeropuerto 23,9 $9^{\circ}$; LogroñoAgoncillo $21,9^{\circ}$ ). Se trata de la zona en que el calor alcanza las cotas más altas, debido a la dinámica atmosférica y a las caracteristicas del territo- 
rio, de cuenca cerrada, en la que el calor se agarra con fuerza en las largas jornadas estivales.

La Cuenca de Pamplona y Navarra Media occidental tienen temperaturas medias de julio superiores a los veinte grados (Pamplona-Observatorio 20,5 ; Ayegui-Irache $\left.20,9^{\circ}\right)$. Resultados ligeramente superiores al periodo internacional anterior (Pamplona-Observatorio 20,2 $2^{\circ}$. La Cuenca de Pamplona registra días de fuerte calor a lo largo del mes, sobre todo en la segunda quincena. El calor almacenado en condiciones anticiclónicas, con pantanos barométricos o bajas térmicas, sin inestabilidad suficiente como para dar lugar a tormentas, origina altas temperaturas que, en muchas ocasiones, no descienden hasta bien entrada la noche. Se trata de días que se soportan mal, incluso con calor agobiante que no se aprecia en los valles situados al norte de la cuenca, en que una brisa fres$\mathrm{ca}$, el cierzo, suele soplar produciendo un descenso térmico.

El Corredor del Arakil, la Llanada de Vitoria y los Valles Cantábricos obtienen temperaturas medias inferiores a los sectores anteriores, que alcanzan los dieciocho grados, por lo que se trata de zonas más moderadas (Alsasua $18,4^{\circ}$; Vitoria-Foronda $18,5^{\circ}$; Villanueva de valdego-

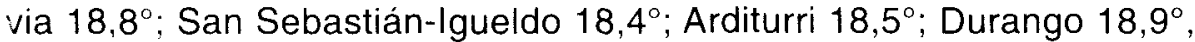
Aranzazu $17,4^{\circ}$ ). Resultados inferiores en el caso de Vitoria a los del periodo internacional anterior (Vitoria-Foronda $18,9^{\circ}$; San Sebastiánigueldo $18,4^{\circ}$ ). Algunos valles vizcainos y guipuzcoanos obtienen registros más altos, parecidos a los de la Cuenca de Pamplona (Bilbao 19.7 ; Hondarribia $20,1^{\circ}$; Santesteban $20,7^{\circ}$ ). Resultados ligeramente superiores a los del periodo internacional anterior (Bilbao-Sondica $19.5^{\circ}$ ). Este inferior grado de calor con respecto a sectores anteriores es debido primeramente a la mayor exposición de esta zona a las irrupciones frias septentrionales, que rozan los Valles Cantábricos y producen descensos térmicos. y en segundo lugar al poder atemperante del cantábrico, que se traduce en la consecución de una moderación al mediodia $y$ a la noche.

En las áreas montañosas, las temperaturas medias son más bajas, $y$ se situan por debajo de los diecisiete grados. El compartimentado relieve y la situación elevada de los observatorios influye en la obtención de tan bajos registros (Abaurrea Alta 16,4 $4^{\circ}$; Remendia 15, $9^{\circ}$; Jaurrieta $16,4^{\circ}$; Urbasa $16^{\circ}$ ). En algunas jornadas de verano se suele observar la aparición de masas neblinosas que atraviesan las montañas $y$ caen sobre los valles; muchas veces sucede esto a primeras horas de la tarde, dando lugar a un descenso de las temperaturas. 
Existen diferencias importantes entre unos julios y otros, si se observan las temperaturas medias de la serie. El julio más frío fue 1980 en san-Sebastián-Igueldo, 1966 en Pamplona-Observatorio, 1977 Zaragoza-Aeropuerto y 1975 en Abaurrea Alta $\left(16,5^{\circ} ; 17,7^{\circ} ; 13,3^{\circ}\right.$ Y $21,3^{\circ}$ respectivamente) y el más cálido 1983 en Zaragoza-Aeropuerto, Abaurrea Alta y Pamplona-Observatorio y 1971 en san-Sebastián-Igueldo $\left(26,7^{\circ}\right.$; $19,5^{\circ} ; 22,9^{\circ}$ Y $20,5^{\circ}$ respectivamente), por lo que el recorrido supera los seis grados en los Valles Pirenaicos, los cinco en Zaragoza y Pamplona $y$ alcanza los cuatro en San Sebastián (Abaurrea Alta 6,2 $2^{\circ}$; Pamplona-Observatorio 5,2 $2^{\circ}$; Zaragoza-Aeropuerto $5,4^{\circ}$; San Sebastián-Igueldo de $4^{\circ}$ ).

El coeficiente de variación muestra la escasa dispersión de las temperaturas medias de julio, con respecto al resto del año, puesto que se sitúa en el seis por ciento en la mayor parte de observatorios, salvo en Zaragoza que desciende al cinco por ciento $y$ en los Valles Pirenaicos que sube al nueve por ciento.

El ritmo estacional entre los tres meses de verano, que se puede apreciar con la observación de la diferencia en grados entre la temperatura media de julio con la de los otros dos meses de verano, muestra cómo es el ascenso $y$ descenso térmico, $y$ cómo aumentan $y$ disminuyen las temperaturas. El ascenso térmico con respecto al mes de mayo es importante, normalmente entre tres y cuatro grados, lo cual quiere decir que se camina hacia el verano con rapidez. Destaca el mayor ascenso del Valle del Ebro, seguido de los Vallesi pirenaicos y las Cuencas Intermedias y la inferior subida de los Valles Cantábricos (San Sebastián-Igueldo 2,6 ; Abaurrea Alta $3,7^{\circ}$; Pamplona-Observatorio $3,5^{\circ}$; Zaragoza $4,2^{\circ}$ ).

El ascenso térmico de julio con respecto a junio es menos pronunciado y oscila en todo el territorio entre dos y tres grados y presenta un aumento de sur a norte, es decir más suave los Valles Cantábricos y más pronunciado en el resto (San Sebastián-Igueldo 2,3 $3^{\circ}$; Abaurrea Alta $3,1^{\circ}$; Pamplona-Observatorio $3,1^{\circ}$; Zaragoza-Aeropuerto $3,3^{\circ}$ ). En el mes de agosto las temperaturas se mantienen con respecto al mes de julio y los observatorios presentan comportamientos diferentes. La Cuenca de Pampiona y el Valle del Ebro resgistran ligero descenso, la Llanada de Vitoria y el Corredor del Arakil repite y los Valles Cantábricos y pirenaicos presentan ligero ascenso (San Sebastián-ig e1do 0,3 $3^{\circ}$; Abaurrea Alta $0,3^{\circ}$; Pamplona-Observatorio $-0,3^{\circ}$; Zaragoza-Aeropuerto $-0,5^{\circ}$ ).

Algunas situaciones atmosféricas son tipicas de los meses de verano. En primer lugar el tiempo anticiclónico tipico de junio, en que todavia las temperaturas no son muy cálidas de verano, pero que se nota una desigual 
distribución térmica por las diferentes comarcas navarras. Una situación habitual de julio, es la formada por bajas presiones relativas, sinónimo de calor, sobre todo en el Valle del Ebro. Entonces, en los mapas de altura aparece sobre nuestro territorio una dorsal anticiclónica, por lo que la estabilidad es alta y el peligro de tormentas minimo. En el mes de agosto suele refrescar con situación de alivio térmico, cuando llegan masas de aire polares, frias para la época en que estamos, que originan un descenso térmico.

El periodo estival se caracteriza por el alto grado de calor, sobre todo en las horas centrales del dia, bien presente en las temperaturas medias de las máximas de julio. El Valle del Ebro registra los valores más altos, superiores a los veintinueve grados. Dentro de este sector, el bajo Ebro y la Ribera navarra superan los treinta gradbs y Navarra Media los veintinueve (Zaragoza-Aeropuerto 30,6 ; Logroño-Agoncillo 29,1 ${ }^{\circ}$; CarcastilloLa Oliva $30,7^{\circ}$; Fitero $30^{\circ}$; Yesa $29,5^{\circ}$; Alloz y Olite $29^{\circ}$ ). Resultados algo superiores a los del periodo internacional anterior (Zaragoza-Aeropuerto $31,4^{\circ}$; Logroño-Agoncillo $28,8^{\circ}$ ).

La Cuenca de Pamplona forma un segundo subsector en el que las temperaturas medias de las máximas de julio superan los veintiséis grados (Pamplona-Observatorio $26,8^{\circ}$ ). El Corredor del Arakil, la Llanada de Vitoria y los Valles Cantábricos anotan valores inferiores entre veinticua-

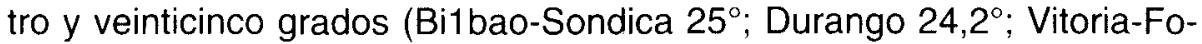

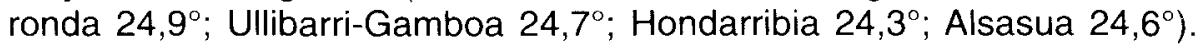
Resultados iguales al periodo internacional anterior.

Los Valles Cantábricos situados a cierta altura registran la temperatura media de las máximas más bajas (Artikutza $23^{\circ}$; Arditurri $23,1^{\circ}$; Aranzazu $21,7^{\circ}$ ). Se trata de lusares que, en que la suavidad viene dada por la influencia del cantábrico, que modera las temperaturas e impide un caldeamiento nocturno intenso y un enfriamiento nocturno pronunciado. Es curioso observar que en verano se igualan las temperaturas en dos sectores tan diferentes como son los Valles Cantábricos y los pirenaicos. Sin embargo, pese a que los registros térmicos de ambos sean parecidos, el clima es muy diferente. En los Valles Cantábricos, de dia las temperaturas no ascienden hasta valores altos y de noche la moderaci6n es la nota dominante. Por el contrario, en los pirineos en las horas centrales del dia el calor aprieta firme y a la noche enfria mucho el ambiente, por lo que la oscilación es elevada.

Los observatorios de la Transición son susceptibles, en algunas ocasiones, de alcanzar temperaturas máximas absolutas de julio importantes con olas de calor, que tienen lugar cuando se instalan bajas presiones al 
suroeste de Portugal que meten aire del sur. Se han alcanzado los treinta y ocho grados en todo el territorio, salvo en los Valles Pirenaicos y otras áreas; y en el Valle del Ebro han superado los cuarenta y dos grados (Bilbao-Sondica $40,4^{\circ}$; San Sebastián-Igueldo $38^{\circ}$; Hondarribia $39,6^{\circ}$; Vitoria- Foronda $38,4^{\circ}$ Pamplona-Observatorio $41,2^{\circ}$; Logroño-Agoncillo $42,8^{\circ}$; Zaragoza-Aeropuerto $42,6^{\circ}$; Abaurrea Alta $34^{\circ}$ ).

Es interesante saber el comportamiento de las diversas comarcas de la Transición con respecto a las temperaturas medias de las mínimas de julio para saber la intensidad que alcanza el frío nocturno. El bajo Valle del Ebro es el lugar en donde se obtienen los valores más altos que indican el escaso enfriamiento nocturno y la dificultad para conciliar el sueño (Zaragoza-Aeropuerto $17,3^{\circ}$ ). El resto de los observatorios de la Ribera, Navarra Media y los Valles Cantábricos, registran temperaturas medias de las mínimas de julio superiores a catorce grados, con algunas diferencias entre los distintos lugares. (Cadreita y Sartaguda 15, $1^{\circ}$; Logroño-Agoncillo $15,2^{\circ}$; Yesa $15^{\circ}$; Olite $15,1^{\circ}$; San Sebastián-Igueldo $15,3^{\circ}$; Hondarribia $15,9^{\circ}$ ). Resultados bastante parecidos a los del periodo internacional aneterior (San Sebastián-Igueldo 15,4 $4^{\circ}$; LogroñoAgoncillo $14,9^{\circ}$ ).

Las Cuencas Intermedias tienen temperaturas medias de las mínimas más bajas. Pamplona registra datos algo inferiores a Bilbao y ambos superiores a Vitoria (Bilbao-Sondica 14,4 $4^{\circ}$; Pamplona-Observatorio 14,1 ${ }^{\circ}$; Vitoria-Foronda $12^{\circ}$ ). Resultados idénticos en Bilbao a los del periodo internacional anterior y más bajos en las Cuencas Intermedias (Bilbao-Sondica $14,4^{\circ}$; Pamplona-o servatorio $13,5^{\circ}$; Vitoria-Foronda $12,8^{\circ}$ ). Algunos observatorlos de los Valles Cantábricos no alcanzan los catorce grados (Durango 13,6 ; Arditurri 13,9 $9^{\circ}$; Aranzazu 13,2 $2^{\circ}$. Donde el frío de verano se deja sentir con más fuerza es en los Valles pirenaicos y montañas altas del territorio. (Abaurrea Alta $9,4^{\circ}$ )

Las temperaturas mínimas absolutas obtenidas en los observatorios del territorio muestran el ambiente frío que pueden alcanzar los distintos sectores de la transición en julio. En las Cuencas Intermedias el termómetro ha bajado de los seis grados en alguna ocasión y en Logroño y Zaragoza de los nueve grados. La mínima absoluta más alta la registra San Sebastián en donde la temperatura no ha bajado de los nueve grados (San Sebastián-Igueldo 9,4\%; Logroño-Agoncillo $8,8^{\circ}$; Zaragoza-Aeropuerto $8^{\circ}$; Vitoria-Foronda $4,8^{\circ}$; Pamplona-Observatorio $5,4^{\circ}$ ). Los Valles Pirenaicos pueden llegar a tener noches de auténtico frío (Abaurrea Alta $1^{\circ}$ ) 


\subsection{Los otoños variables}

Al igual que primavera, otoño es una estación puente entre el verano caluroso y seco y el invierno frío y lluvioso, y como todas las transiciones, es un periodo de contrastes en el que alternan tipos de tiempo diferentes y a veces desconcertantes. El paso del verano al otoño no se hace de un modo gradual, sino que varia de un año a otro, con avances y retrocesos, al igual que ocurría con primavera, sólo que en otoño la influencia del verano se deja sentir con mayor fuerza, sobre todo en el primer mes. También la circulación de la atmósfera experimenta cambios notables con respecto al estío. El anticiclón subtropical de las Azores, se debilita y emigra hacia lugares más meridionales y por lo tanto más alejados. Entrado el otoño suele suceder al igual que en primavera, la alternancia de jornadas soleadas, sin lluvias, denominadas veranillos con días lluviosos originados por el paso de borrascas del frente polar.

Si se tiene en cuenta el limite de la temperatura media de $10^{\circ}$ para saber si se puede calificar a algún mes otoñal como frío de invierno, resulta que en los Valles Cantábricos ningún mes tiene caracteres invernales; noviembre seria invernal en el Valle del Ebro, en las Cuencas Intermedias y en algunos observatorios de las cabeceras de los Valles Cantábricos; y octubre y noviembre en los Valles Pirenaicos y áreas montañosas de la transición (Abaurrea Alta, Urbasa).

Es interesante conocer las temperaturas medias de octubre, mes típico de otoño. Como las distintas comarcas del territorio considerado tienen diferencias en cuanto a la altitud se ha calculado el gradiente térmico vertical de las temperaturas medias de octubre, siendo de $0,70^{\circ}$ de disminución cada cien metros de altitud a partir de $16,499^{\circ}$ de temperatura, con un coeficiente de correlación alto $\left(r^{2}=0,9093\right)$.

Los observatorios más cálidos de los Valles Cantábricos y el bajo valle del Ebro registran el octubre más moderado con temperaturas medias superiores a los quince grados, e incluso se alcanzan los dieciséis en algún observatorio más soleado (Bilbao-Sondica $16^{\circ}$; San Sebastián-Igueldo $15,2^{\circ}$; Santesteban 15,3 ; Hondarribia 15, $7^{\circ}$; Zaragoza-Aeropuerto $15,4^{\circ}$ ). Resultados similares a los obtenidos en el periodo internacional 1931-60 y aigo más elevados en San Sebastián (Bi1bao-Sondica 15,9 $9^{\circ}$ : San Sebastián-lgue1do $14,6^{\circ}$; Zaragoza-Aeropuerto $15,4^{\circ}$ ). Algunos observatorios de los Valles Cantábricos, bien por la mayor altitud en que se encuentran, bien por el mayor alejamiento del cantábrico, o por ambas cosas, resultan

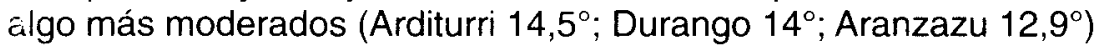


El alto Valle del Ebro, Navarra Media y la Ribera, superan los catorce grados de temperatura media (Logroño- Agoncil10 14,4 $4^{\circ}$; Buñue 1 14,7 Carcasti110-La Oliva $14,1^{\circ}$; Alloz $14,7^{\circ}$; Yesa $14,2^{\circ}$ ). La Llanada de Vitoria, el Corredor del Arakil y la Cuenca de Pamplona registran temperaturas medias de octubre inferiores y próximas o ligeramente superiores a los trece grados, aunque Pamplona es casi un grado más cálida que Vitoria y Alsasua (Pamplona- Observatorio $13,9^{\circ}$; Vitoria-Foronda $12,8^{\circ}$; Villa-

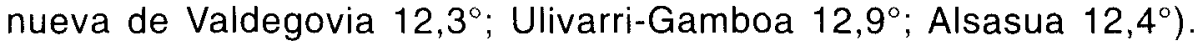
Resultados superiores a los registrados en el periodo internacional anterior en Pamplona y Logroño y parecidos en Vitoria (Pamplona-Observatorio $13,4^{\circ}$; Logroño-Agoncillo $14^{\circ}$; Vitoria-Foronda $12,7^{\circ}$ ). Los Valles Pirenaicos y áreas montañosas obtienen las temperaturas medias de octubre más bajas (Abaurrea Alta $9,5^{\circ}$; Urbasa $9,6^{\circ}$ ).

Existen diferencias importantes entre unos octubres y otros, si se observan las temperaturas medias de la serie. El octubre más frio en San Sebastián-Igue1do, Pamplona- observatorio, Zaragoza-Aeropuerto y Abaurrea Alta fue $1974\left(10^{\circ} ; 8,8^{\circ} ; 11,7^{\circ}\right.$ y $4,9^{\circ}$ respectivamente) y el más cálido 1968 en San Sebastián-Igueldo y Pamplona-Observatorio, 1967 en Zaragoza-Aeropuerto y 1988 en Abaurrea Alta $\left(17,7^{\circ} ; 16,7^{\circ} ; 17,3^{\circ} \mathrm{Y} 12,4^{\circ}\right.$ respectivamente), por lo que el recorrido alcanza casi los ocho grados en San Sebastián, Pamplona y Abaurrea Alta y los seis en Zaragoza (San Sebastián-Igueldo de 7,7\%; Pamplona-Observatorio 7,9 $9^{\circ}$; Abaurrea Alta $7,3^{\circ}$; Zaragoza-Aeropuerto $5,6^{\circ}$ ).

El coeficiente de variación, que nos permite comparar la dispersión de las temperaturas medias de octubre, es inferior con respecto al de abril y sıperior al de Julio. Es bajo en el Valle del Ebro (Logroño-Agoncillo 9\%; Zaragoza $9 \%$ ) y aumenta ligeramente en los Valles Cantábricos y en las Cuencas Intermedias (San Sebastián-Igueldo 10\%; Santesteban 10\%; Vitoria-Foronda 11\%; Pamplona-Observatorio $11 \%$ ) y se dispara en los Valies Pirenaicos (Abaurrea Alta 16\%).

El ritmo estacional entre los tres meses de otoño, que se puede apreciar con la observación de la diferencia en grados entre la temperatura de octubre con la de,los otros dos meses de otoño, señala el aumento y la reducción de las temperaturas. El descenso térmico de septiembre con respecto al mes de agosto oscila entre uno y tres grados, es menos significativo en los Valles Cantábricos, aumenta en las Cuencas Intermedias y Valles Pirenaicos y es más alto en el Valle del Ebro; en donde supera los tres grados (San Sebastián-Igueldo $0,8^{\circ}$; Abaurrea Alta 2,8 $8^{\circ}$; PamplonaObservatorio $2,1^{\circ}$; Zaragoza $3,1^{\circ}$ ). 
El descenso térmico de octubre con respecto a septiembre es pronunciado, oscila entre tres y cinco grados y presenta un aumento de norte a sur, es decir más moderado en los Valles Cantábricos, aumenta en las Cuencas Intermedias y Valles Pirenaicos y más elevado en el Valle del Ebro (San Sebastián-Igueldo 2,7 ; Abaurrea Alta 4,1 ${ }^{\circ}$; Pamplona-Observatorio $4,2^{\circ}$; Zaragoza-Aeropuerto $5,3^{\circ}$ ). Por lo tanto, octubre es un mes más frío, en donde aparecen los caracteres tipicos otoñales y se olvidan los estivales.

El descenso térmico de noviembre con respecto al mes de octubre es pronunciado, oscila entre los cuatro y seis grados, siguiendo el esquema, de menos a más, Valles Cantábricos-Valles pirenaicos-Cuencas Intermedias-Valle del Ebro. Este descenso hace pensar en la llegada del invierno, si bien algo atenuada en algunos lugares (San Sebastián- Igueldo $4,3^{\circ}$; Abaurrea Alta 4,9 ; Pamplona-Observatorio 5,4 $4^{\circ}$; Zaragoza-Aeropuerto $\left.5,6^{\circ}\right)$. Por lo tanto, el desenso térmico entre octubre y noviembre es el más elevado del año en dos meses consecutivos.

Algunas situaciones atmosféricas son representativas de los tres meses de otoño. El tiempo del sur de septiembre, formado por una profunda borrasca de amplio radio de acción, que se sitúa al oeste de Portugal y un sistema de altas presiones con centro en el mar Mediterráneo, da lugar a días cálidos. El tiempo anticiclónico de veranillo es característico de octubre. Un anticiclón se suele situar en las Islas Británicas o en el mar del Norte y engloba a la penisnula lbérica por su flanco sur. En noviembre suelen aparecer tiempos fríos que dan lugar a bajas temperaturas, sobre todo cuando llegan situaciones frias septentrionales. Con esta situación los Valles Pirenaicos registran valores térmicos muy bajos y el Valle del Ebro es el que obtiene temperaturas más altas. Las Cuencas Intermedias resultan muy frias.

Los diferentes valores de temperatura media de las máximas de octubre en el territorio de la Transición, dan una idea del grado de calor que alcanza este mes en las horas centrales del dia. Los Valles Cantábricos situados a baja altitud y el bajo Valle del Ebro son los que tienen las temperaturas más altas en las tardes de otoño (Zaragoza- Aeropuerto 20,8 Bi1bao-Sondica $21^{\circ}$; santesteban $20,6^{\circ}$; Hondarribia 20,4 ). El calor diurno es algo inferior en el alto Valle del Ebro, Navarra Media, Ribera y los lugares más moderados de los Valles Cantábricos (Logroño-Agoncillo 19,6 ;

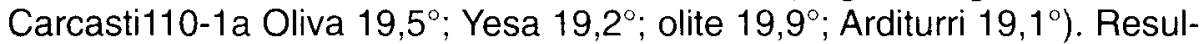
tados inferiores en medio grado al periodo internacional anterior en el Valle del Ebro y ligeramente superior en los valles Cantábricos (Zaragoza-

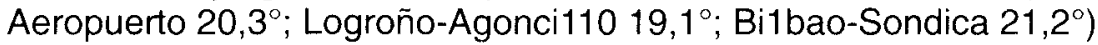


Las Cuencas Intermedias y los Valles Cantábricos menos moderados, situados a mayor altitud y en las cabeceras de los valles obtienen temperaturas máximas en algunas ocasiones de dos grados por debajo del anetrior sector (San Sebastián-Igueldo $18,3^{\circ}$; Durango 18, $3^{\circ}$; Aranzazu $15,8^{\circ}$; Vitoria-Foronda $18^{\circ}$; Ullivarri-Gamboa $17,9^{\circ}$; Pamplona- Observatorio $18,7^{\circ}$ ). Resultados superiores a los registrados en el periodo internacional anterior en San Sebastián y Vitoria y parecidos en Pamplona (San Sebastián-Igueldo $17,3^{\circ}$; Vitoria-Foronda $17,4^{\circ}$; Pamplona-Observatorio $18,8^{\circ}$ ). En los Valles Pirenaicos y en las zonas montañosas el calor a primeras horas de la tarde disminuye, de tal manera que el ambiente frío hace su aparición, incluso en los días anticiclónicos soleados. Cuesta recuperar durante el día las bajas temperaturas nocturnas.

En algunas ocasiones se pueden alcanzar temperaturas elevadas, tal como lo demuestran las temperaturas máximas absolutas de octubre que se sitúan entre los veintiocho y los treinta y tres grados, salvo en los Valles Pirenaicos y otras áreas montañosas que no llegan con mucho a esta cifra (Bilbao-Sondica $33,4^{\circ}$; San Sebastián-Igueldo $30^{\circ}$; Vitoria- Foronda $28^{\circ}$ Pamplona-Observatorio $30^{\circ}$; Logroño-Agoncillo $31^{\circ}$; Zaragoza-Aeropuerto $29,4^{\circ}$; Abaurrea Alta $25^{\circ}$ ).

Los diferentes valores de temperatura media de las minimas de octubre, muestran el grado de frío nocturno que alcanza este mes en las horas más frias de la noche. Los Valles Cantábricos resultan ser los más moderados del territorio, con una temperatura media de las mínimas de octubre que alcanza los once grados (Bilbao-Sondica $11^{\circ}$; Hondarribia $11^{\circ}$ ). Con la altitud y el alejamiento del mar los valores descienden (Durango 9, $8^{\circ}$; Arditurri $9,9^{\circ}$; Aranzazu $10^{\circ}$ ). En el Valle del Ebro, las temperaturas mínimas son más bajas y el frío a la noche se comienza sentir con mayor intensidad. Zaragoza es menos fria que Logroño, la Ribera navarra y Navarra Media. Las temperaturas mínimas de estas últimas superan por poco a las de Pamplona (Zaragoza-Aeropuerto $10^{\circ}$; Logroño-Agoncillo $9,3^{\circ}$ ).

Las Cuencas Intermedias tienen noches más frias, debido principalmente a la altitud y a ser cuencas cerradas rodeadas de montañas en donde la irradiación nocturna es importante, así como el riesgo de embalsamiento de masas de aire frias. Dentro de las cuencas hay que señalar que Vitoria es más fria que Pamplona (Vitoria-Foronda $7,6^{\circ}$; UllibarriGamboa $7,9^{\circ}$; Pamplona-Observatorio $9^{\circ}$ ). Los Valles Pirenaicos y las zonas montañosas, son los lugares con temperaturas mínimas de octubre más bajas que justamente llegan a cuatro grados. Estamos ante noches invernales con valores térmicos muy bajos. 
Las temperaturas minimas absolutas obtenidas en los obsenatorios del territorio muestran el ambiente frío que pueden alcanzar los distintos sectores de la transición en octubre. Excepto en los Valles Cantábricos y bajo Valle del Ebro, se han registrado temperaturas por debajo de los cero grados. En las Cuencas Intermedias y en el alto Valle del Ebro e ha llegado a un grado bajo cero y en los Valles Pirenaicos a cuatro grados bajo cero (Bilbao-Sondica 2,2 $2^{\circ}$; San Sebastián-Igueldo $1,4^{\circ}$; LogroñoAgoncillo $-0,8^{\circ}$; Zaragoza-Aeropuerto $0,6^{\circ}$; Vitoria-Foronda $-1,6^{\circ}$; Pamplona- Observatorio $-0,4^{\circ}$; Abaurrea Alta $-6^{\circ}$ )

En otoño tienen lugar las primeras heladas del año. El número medio de días de helada de otoño en el período estudiado es muy bajo en los Valles Cantábricos, en donde justo llega en noviembre a un día (BilbaoSondica 1; San Sebastián-Igueldo 0,8; Hondarribia 1,6). Es más alto en el Valle del Ebro (Logroño-Agoncillo 2,6 días de helada; Zaragoza-Aeropuerto 2,6) y aumenta en las Cuencas Intermedias, en donde supera los cinco días (Vitoria-Foronda 5,6; Pamplona-Observatorio 5,7; Alsasua $7,6)$. En los Valles Pirenaicos las cifras aumentan considerablemente anotando dicisiete días de helada en los observatorios más altos (Abaurrea Alta 17,1 días de helada).

El primer mes del otoño es raro que hiele, sin embargo en los Valles Pirenaicos la primera fecha extrema de helada se sitúa a finales de septiembre. Octubre no es un mes todavía generalizado de heladas, si bien en algunos años fríos pueden aparecer. La primera fecha extrema se da a mediados en el Corredor del Arakil y en tierra Estella, y a finales en las Cuencas de Pamplona y de Lumbier-Aóiz y en el Valle del Ebro. Finalmente en los Valles Cantábricos se retrasa a primeros de noviembre.

Y estos contrastes en cuanto a los días de helada se ponen de manifiesto al analizar otros datos, como la necesidad de calefacción en grados día en otoño, que permite establecer diferencias en cuanto al consumo de calefacción. Las necesidades de calefacción en otoño son casi la mitad que las de primavera. Los Valles Cantábricos y el Valle del Ebro son los que menos necesidad de calefacción tienen con resultados que se sitúan próximos a los cien y doscientos grados, siendo inferiores en los Valles Cantábricos y superiores en el Valle del Ebro (Bilbao-Sondica 96; San Sebastián-Igueldo 123; Santesteban 138; Zaragoza 156; Logroño 196).

Las Cuencas Intermedias tienen necesidades de calefacción distintas según las zonas: La Cuenca de Pamplona es más suave que la Llanada 
de Vitoria y el Corredor del Arakil es el más frío. En estos lugares la necesidad de calefacción llega a ser más del doble que en Bilbao (Alsasua 315; Vitoria-Foronda 287; Pamplona-Observatorio 229). En los Valles Pirenaicos el índice alcanza valores muy altos (Abaurrea Alta 497).

\section{BIBLIOGRAFIA}

ARLERY, R. GRISOLLET, H. y GUILMET, B. (1973): Climatologie. Méthodes et pratiques, París, Gauthiers-Villards.

COMELLAS, J. L. (1963-64): "Los estados de tiempo en la Cuenca de Pamplona", Geográpbica, X-XI, pp.3-34, Zaragoza.

CREUS NOVAU, J. (1983): "Características agroclimáticas de Navarra", Boletín de información agraria el Campo, 91, pp. 10-14, Bilbao.

CREUS NOVAU, J. (1990): Climatología (Gran Enciclopedia Navarra),Caja de Ahorros de Navarra, Pamplona.

ELIAS CASTILLO, F. Y RUIZ BELTRÁN, L. (1986): Caracterización agroclimática de Navarra, Pamplona, Ministerio de Agricultura, Pesca y Alimentación y Departamento de Agricultura, Ganadería y Montes del Gobierno de Navarra, 226 p.

FERNANDEZ GARCIA, F. (1995): Manual de climatologia aplicada, Madrid, síntesis.

FLORISTÁN SAMANES, A. (1951): La Ribera Tudelana de Navarra, Príncipe de Viana y Juan Sebastián Elcano, 303 p.

FLORISTÁN SAMANES, A. (1975): El clima de Pamplona y de las ciudades vecinas, Pamplona, universidad de Navarra, pp. 45-108.

PEJENAUTE GOÑI, J. (1990): Tipos de tiempo y clima de las Comarcas Navarras (tesis de doctorado), Pamplona, Gobierno de Navarra, Príncipe de Viana.

PEJENAUTE GOÑI, J.M. (1992): El clima de Navarra, Pamplona, Ediciones Eunate, $223 \mathrm{p}$.

PEJENAUTE GOÑI, J. (1993): El clima de Pamplona, Pamplona, Ayuntamiento de Pamplona, $104 \mathrm{p}$.

PEJENAUTE GOÑI, J. (1994): El tiempo en Navarra, Pamplona, Gobierno de Navarra, Departamento de Agricultura, Ganadería y Montes, Colección Temas de Navarra, $n^{\circ} 12,104 p$.

PEJENAUTE GOÑI, J. (1998): "Evolución de las temperaturas medias recientes en Navarra", Espacio, tiempo y forma, Homenaje a José Estébanez, serie VI, Geografia, t. 11, pp. 31-58.

RASO, J.M. (1987): "Variaciones recientes de la temperatura media en el observatorio del Ebro". Madrid, Anales Universidad Complutense, 7, pp.155-165. 
RASO, J.M. (1994): "Evolución reciente de las temperaturas medias anuales en España". Barcelona, Avances en climatologia histórica en España, Barcelona, Oikostau, pp. 91-123.

RASO, J.M.i MARTIN VIDE, J. Y CLAVERO, P. (1987): Estadistica básica para Ciencias Sociales. Barcelona, Ariel.

RUIZ URRE S TARAZ U, E.(1982): La transición climática del cantábrico Oriental al Valle Medio del Ebro, Vitoria, Diputación provincial de Alava, $651 \mathrm{p}$. 